Illinois State University

ISU ReD: Research and eData

Theses and Dissertations

$3-24-2017$

\title{
Veterinarians and Their Perception of the Treatment of Animal Abuse Cases in the Criminal Justice System
}

Dustin A. Richardson

Illinois State University, drichardson1191@gmail.com

Follow this and additional works at: https://ir.library.illinoisstate.edu/etd

Part of the Criminology Commons, and the Criminology and Criminal Justice Commons

\section{Recommended Citation}

Richardson, Dustin A., "Veterinarians and Their Perception of the Treatment of Animal Abuse Cases in the Criminal Justice System" (2017). Theses and Dissertations. 705.

https://ir.library.illinoisstate.edu/etd/705

This Thesis is brought to you for free and open access by ISU ReD: Research and eData. It has been accepted for inclusion in Theses and Dissertations by an authorized administrator of ISU ReD: Research and eData. For more information, please contact ISUReD@ilstu.edu. 


\title{
VETERINARIANS AND THEIR PERCEPTION OF THE TREATMENT OF ANIMAL ABUSE CASES IN THE CRIMINAL JUSTICE SYSTEM
}

\author{
Dustin A. Richardson
}

80 Pages

Americans love their companion animals. In 2015, nearly two-thirds (65\%) of all households in the U.S. housed at least one pet (APPA, n.d.). This love does not translate to policy, however, as many animals are left defenseless. Interestingly, the Animal Legal Defense Fund (2016) has ranked Illinois' animal protection laws as the strongest in the nation for the last eight years. Extant animal abuse research is almost exclusively concerned with the ramifications that the abuse has for humans, and there is a dearth of social science research that examines veterinarians and the criminal justice system. Extremely limited research on this subject suggests that veterinarians are not satisfied with how the criminal justice system handles reports of animal abuse.

The current study was designed to explore veterinarians' familiarity with animal abuse and experience with the criminal justice system. The researcher was particularly interested in whether veterinarians were satisfied with the criminal justice system's response to animal abuse. Additionally, the study explored what these individuals believed an appropriate response to animal abuse would consist of. There were not any hypotheses as the research was meant to be purely exploratory.

To achieve these goals, the researcher conducted semi-structured qualitative interviews with veterinarians. Participants were recruited by way of a convenience sampling procedure 
with McLean County, Illinois serving as the research site. Findings indicate that veterinarians seldom encounter animal abuse, and they interact with the criminal justice system even less frequently. The interactions they have had with the criminal justice system have not been pleasant, with every participant being left unsatisfied after participating in criminal cases. If these veterinarians had their way, the criminal justice system would take animal abuse more seriously and punish animal abusers more harshly.

KEYWORDS: Animal Abuse, Animal Cruelty, Veterinarians, Criminal Justice System, Perceptions, Opinions 
VETERINARIANS AND THEIR PERCEPTION OF THE TREATMENT OF ANIMAL

ABUSE CASES IN THE CRIMINAL JUSTICE SYSTEM

DUSTIN A. RICHARDSON

A Thesis Submitted in Partial

Fulfillment of the Requirements

for the Degree of

\section{MASTER OF SCIENCE}

Department of Criminal Justice Sciences

ILLINOIS STATE UNIVERSITY 
(C) 2017 Dustin A. Richardson 
VETERINARIANS AND THEIR PERCEPTION OF THE TREATMENT OF ANIMAL ABUSE CASES IN THE CRIMINAL JUSTICE SYSTEM

DUSTIN A. RICHARDSON

COMMITTEE MEMBERS:

Shelly Clevenger, Chair

Philip Mulvey

Jacqueline Schneider 


\section{ACKNOWLEDGMENTS}

First and foremost, I would thank Dr. Shelly Clevenger for serving as Chairperson of this thesis committee. During the construction of this research and my time at Illinois State University, she has served as not only a mentor but a friend and because of her this research is possible. I would hate to think about how difficult all of this would have been had Dr. Clevenger not been so supportive throughout the entire process. I also want to express gratitude to the other committee members, Dr. Phil Mulvey and Dr. Jackie Schneider, for agreeing to serve as mentors to me during this important next step in my education. Your expertise and support certainly enabled me to comfortably navigate this important research. I would be remiss if I did not thank Dr. Cara Rabe-Hemp as well. It was her suggestion that provided the groundwork for this research, and I am not sure the project would have been conceived without her wisdom.

I would also like to extend gratitude to the five veterinarians that participated in this research. Though the reader will merely know them as an anonymous figure, their willingness to spend free time with an aspiring scholar will never be forgotten by the researcher. I commend each one of you for the sacrifices you make for a population that could not be more deserving. Lastly, I would like to extend many thanks to my incredible wife, Courtney. My career as a student has uprooted our lives once and will do so again soon, sometimes placing the pursuit of her own goals on hold. Through it all, she has remained selfless, and I am forever indebted.

D. A. R. 


\section{CONTENTS}

Page

ACKNOWLEDGMENTS

$\begin{array}{ll}\text { CONTENTS ii } & \text { ii }\end{array}$

TABLES

CHAPTER

I. INTRODUCTION 1

II. $\quad$ LITERATURE REVIEW $\quad 4$

Definition of Animal Abuse 4

Prevalence of Animal Abuse $\quad 7$

$\begin{array}{ll}\text { Offenders } & 11\end{array}$

Animal Abuse Statutes $\quad 14$

The Link Between Animal Abuse and Subsequent Interpersonal Violence 18

$\begin{array}{ll}\text { Theoretical Framework } & 23\end{array}$

Agnew's Theory of Animal Abuse 25

The Criminal Justice System’s Response $\quad 29$

Veterinarians’ Perception of Animal Mistreatment 31

III. METHODS 33

$\begin{array}{ll}\text { Purpose of Study } & 33\end{array}$

Sample $\quad 33$

Recruitment of Participants 34

Instrumentation $\quad 35$

$\begin{array}{ll}\text { Analysis Plan } & 37\end{array}$

IV. DATA ANALYSIS 38

$\begin{array}{ll}\text { Overview of Sample } & 38\end{array}$

Demographics 39

Professional Experiences with Animal Abuse 39 
Familiarity with Animal Abuse $\quad 40$

Handling Animal Abuse 44

Interaction with the Criminal Justice System $\quad 50$

Involvement with the Criminal Justice System $\quad 50$

Perceptions of the Criminal Justice System's Treatment of Animal Abuse

Cases

$\begin{array}{ll}\text { V. DISCUSSION } & 60\end{array}$

$\begin{array}{ll}\text { Discussion } & 60\end{array}$

$\begin{array}{ll}\text { Limitations } & 66\end{array}$

$\begin{array}{ll}\text { Recommendations and Conclusion } & 67\end{array}$

$\begin{array}{ll}\text { REFERENCES } & 70\end{array}$

$\begin{array}{ll}\text { APPENDIX A: INTERVIEW GUIDE } & 75\end{array}$

APPENDIX B: TELEPHONE SCRIPT / EMAIL LETTER 76

APPENDIX C: VOLUNTARY INFORMED CONSENT FORM FOR INTERVIEW 77

APPENDIX D: VOLUNTARY CONSENT FORM FOR INTERVIEW 79

APPENDIX E: WITHDRAWAL STATEMENT 80 


\section{TABLES}

Table

Page

1. Reported Animal Abuse Cases by Year, 2000-2015

2. Abuse Classifications

3. Animals in Abuse Cases

4. Age of Offenders

5. Parties Reporting Animal Abuse

6. Demographics

7. Participant Summaries 


\section{CHAPTER I}

\section{INTRODUCTION}

Americans love their companion animals. In 2015, nearly two-thirds (65\%) of all households in the U.S. housed at least one pet, which equates to 312.1 million pets living in 79.7 million homes (APPA, n.d.). We "have anthropomorphized animals and because of that, [we] are held to a new standard of care" (Navarro \& Schneider, 2013, p. 148). U.S. laws have not always reflected this love, and we have yet to reach this "new standard of care" that we owe to animals. Over the last decade, a significant amount of protections under U.S. law has been extended to animals as society and lawmakers recognize the plight of animals, yet much of the research community has failed to follow suit (Burchfield, 2016).

The animal abuse literature that does exist is almost exclusively concerned with the ramifications that animal abuse has for human beings. Felthous and Kellert (1986) found eight common motivations for animal abuse that are primarily the result of enhanced aggression within the abuser. The common belief is that this experience with violence against animals has the potential to predispose individuals to commit acts of violence against humans. Research has found that such a belief is justified (Arkow, 2014; Arluke \& Madfis, 2014; Dadds, Whiting, \& Hawes, 2006; Hensley \& Tallichet, 2005). These findings certainly have important implications in social science, but so too do the other aspects of animal abuse that have been neglected by the research community. As Jeremy Bentham (1789) put it, "[t]he question is not, Can they reason? Can they talk? but, can they suffer?" (as cited in Beirne, 1999, p. 131). The only study to examine veterinarians' experiences with and perceptions of the agencies tasked with 
investigating animal abuse found that, "[s]ome respondents were skeptical that legal intervention would improve conditions for the animal and expressed great frustration about the perceived inaction on the part of authorities or of being told that nothing could be done after a complaint was lodged" (Donley, Patronek, \& Luke, 1999, p. 69).

Robert Agnew constructed a comprehensive theory of animal abuse that is composed of two parts. The first part includes the "individual factors that directly increase the propensity for animal abuse" (Agnew, 1998, p. 181). The three individual factors contributing to the likelihood that an individual will abuse an animal are the ignorance regarding the negative consequences that animals experience as a result of abuse, the belief that animal abuse is not wrong, and the belief that there is something to benefit from abusing animals. The second part of the Agnew's theory includes "an additional set of factors that have both direct effects on animal abuse and indirect effects through the above three factors" (1998, p. 182). These factors include individual traits, socialization, strain, level of social control, the animal's nature, social position, gender, and other socio-demographic variables. While this theory has not been tested, it is primarily composed of other well-tested and well-supported theories of crime.

This research is intended to help close the gap in the existing literature. It sought to explore the experiences of these professionals and whether they had interacted with the criminal justice system as a result of animal abuse. The research also examined whether veterinarians were satisfied with the criminal justice system's response to animal abuse. Additionally, the study explored what these individuals believed an appropriate response to animal abuse would consist of. There were not any hypotheses as the research was meant to be purely exploratory.

To achieve these goals, the researcher conducted semi-structured qualitative interviews with veterinarians. Participants were recruited by way of a convenience sampling procedure. 
All veterinary clinics in McLean County, Illinois were contacted to participate in the study. Interviews were conducted face-to-face on a one-on-one basis with participants unless they specifically requested a telephone interview. An interview guide (APPENDIX A) was used to ensure that all major themes were discussed; however, each participant could speak freely about their experiences with animal abuse and the criminal justice system. All interviews were recorded, with the participants' consent, so that the researcher was better able to analyze the data. Recordings were transcribed verbatim, and the researcher read over each transcript as many times as necessary to identify all themes that appeared. These themes were used to construct a category key in order to refine each category so that every theme was placed within the appropriate category.

The findings from this study could potentially assist in developing training that would better prepare the criminal justice system in its efforts to punish and deter animal abuse and potentially aid in forging a more effective alliance between veterinarians and the criminal justice system. 


\section{CHAPTER II}

\section{LITERATURE REVIEW}

\section{Definition of Animal Abuse}

In defining animal abuse, researchers and other professionals have failed to reach a consensus, as definitions are influenced by a host of factors. This can include how the individual defining animal abuse was raised, his or her personal experiences, the standards of the culture he or she belongs to, his or her religious and/or spiritual beliefs, as well as other variables (Arkow \& Lockwood, 2013). As a result, there is a range of varying definitions, which has proved to be a hindrance to the development of the study. Some researchers prefer the term "animal abuse" over the term "animal cruelty" (see Ascione \& Shapiro, 2009). "Animal cruelty" implies that the acts were committed maliciously, which excludes neglect, which is the most common form of animal abuse (Ascione \& Shapiro, 2009).

There are several other challenges that make constructing a definition a daunting task. As will be discussed later, animal abuse statutes frequently contain "vague, ambiguous, and archaic language" (Arkow \& Lockwood, 2013, p. 12). Vague language serves to protect socially acceptable forms of animal abuse, such as euthanasia, veterinary procedures, and factory farming. Terms like "proper care," "unnecessary suffering," and "needless mutilation" create ambiguity, making abuse difficult to properly define (p. 12). Ascione (1993) defined animal cruelty as "[s]ocially unacceptable behavior that intentionally causes unnecessary pain, suffering, or distress to and/or death of an animal" (p. 228). Furthermore, statutes are often outdated and contain archaic language from the $19^{\text {th }}$ Century that seldom applies to the current culture in the 
U.S. The lack of objective, standardized scales for detecting animal abuse also contributes to the difficulty of defining the abuse (Arkow \& Lockwood, 2013). Veterinarians are forced to rely on cultural standards that vary greatly throughout the country and within states and even communities. Arkow (2003) created a set of guidelines that would aid veterinarians in the detection of animal abuse by sensitizing them to animal and human welfare concerns, environmental concerns, physical injures to the animal, and sexual abuse of the animal (see Arkow, 2003). However, these standards have not been incorporated into standard veterinary practice. Another problem with defining animal abuse involves establishing a motive for the abuse (Arkow \& Lockwood, 2013). The most common form of animal abuse is neglect, and it is generally not done maliciously. However, the result is the same: the animal suffers. Some definitions are concerned with establishing a motive while others are only concerned with the result of the action. For instance, Felthous and Kellert (1987b) defined a "pattern of deliberately, repeatedly, and unnecessarily hurting vertebrate animals in a manner likely to cause serious injury” as substantial animal cruelty (p. 1715). Additionally, Ascione and Shapiro (2009) defined animal abuse as "[n]onaccidental, socially unacceptable behavior that causes pain, suffering or distress to and/or the death of an animal" (p. 570). Agnew (1998), as discussed below, did not include the need for establishing a motive. Surprisingly, determining how to define "animal" has also proved to be a difficult task for researchers and lawmakers (Arkow \& Lockwood, 2013), as it must be determined if "animal" includes only vertebrates, or should it also include all non-human animals including insects?

There are myriad definitions of animal abuse, but most definitions are composed of three recurring themes. Animal abuse is generally defined in academic research as an action that inflicts harm on an animal and is "(1) socially unacceptable, (2) intentional or deliberate, and/or 
(3) unnecessary" (Agnew, 1998, p. 179). By excluding socially acceptable and unintentional acts from the definition, only a small number of the abuses animals experience will be classified as such (Agnew, 1998). Factory farming, laboratory experimentation, and animal testing for commercial products have all been deemed acceptable by society even though billions of animals suffer because of each (Cazaux, 1999). Although neglect is generally the result of a lack of education or a temporary lapse in judgment, the animal still suffers (Arkow \& Lockwood, 2013). Definitions requiring that abusers intentionally harm their victims fail to acknowledge the countless victims of neglect. Finally, the use of "unnecessary" makes definitions subjective. When developing a comprehensive theory of the causes of animal abuse, Agnew (1998) employed the following definition: "[a]ny act that contributes to the pain or death of an animal or that otherwise threatens the welfare of an animal" (p. 179). Agnew (1998) clarified that the "abuse may be physical (including sexual) or mental, may involve active maltreatment or passive neglect, may be direct or indirect, intentional or unintentional, socially approved or condemned, and/or necessary or unnecessary (however defined)" (p. 179). Constructing such an all-inclusive definition of animal abuse has several strengths (Agnew, 1998). The clear majority of animal abuses (e.g., factory farming, experimentation, neglect) are captured by this definition. Prevailing societal beliefs do not dictate whether an action causing harm or death to an animal is defined as abuse. This definition also enables researchers to examine acts of animal abuse that have not been criminalized. Given that billions of animals suffer every year as a result of legal activities (Cazaux, 1999), it is important for researchers to focus attention on these activities.

Before the study of animal abuse can effectively combat the abuse, an appropriate and universally accepted definition must be developed. Constructing such a definition is not within the scope of this study, however. For the purposes of this study, Agnew's definition will be 
employed for the reasons listed above. To be sure, this research examines how veterinarians perceive the criminal justice system's response to animal cruelty, and because the justice system is unable to punish individuals unless the break the law, an edited version of Agnew's definition will be employed: Animal abuse is any illegal act that contributes to the pain or death of an animal or that otherwise threatens the welfare of an animal.

\section{Prevalence of Animal Abuse}

Constructing a general definition of animal abuse may be difficult, but defining individual acts of animal abuse appears to be a simpler task. In 2002, Pet-Abuse.com (2016), a non-profit organization, created a national database, Animal Abuse Registry Database Administration System (AARDAS). The database only records information regarding known cases of animal abuse. It contains 22 different categories of abuse, which are identified and tracked. These include: beating, bestiality, burning - caustic substance, burning - fire or fireworks, choking/strangulation/suffocation, drowning, fighting, hanging, hoarding, kicking/stomping, mutilation/torture, neglect/abandonment, other, poisoning, shooting, stabbing, theft, throwing, unclassified, unlawful trade/smuggling, unlawful trapping/hunting, and vehicular (Pet-Abuse, 2016). This list of categories is more specific than others, such as Arkow and Lockwood's (2013), which only includes animal cruelty, animal abuse, neglect, hoarding, animal physical abuse, non-accidental injury (NAI), animal sexual abuse, and emotional abuse. In addition to collecting information on the types of abuse, AARDAS collects data on the types of animals abused, the gender of the abuser, the locations where the events occurred, as well as many other aspects of the cases.

Pet-Abuse.com is a useful tool for anyone researching animal cruelty, as currently there is no official national database available to the public that records animal cruelty cases. 
However, on January 1, 2016, the Federal Bureau of Investigations (FBI) began collecting data on animal cruelty for their National Incident-Based Reporting System (NIBRS) (FBI, 2016). Unfortunately, it will be a few years before patterns begin to form, making Pet-Abuse.com the preferred database at the time of writing. In addition to the lack of an official database of animal cruelty cases, instances of animal cruelty often go unreported because of its secret nature (Felthous \& Kellert, 1987a).

The following statistics were taken from Pet-Abuse.com on June 9, 2016 (PetAbuse.com, 2016). While AARDAS is currently the most comprehensive database, it is important to remember that it only collects data on known instances of animal abuse. Extensive research on the "dark figure of crime" has found that less than half of all crimes are reported. Another major limitation of the database is that the number of cases they report varies without any clarification as to why. With that said, the following figures are still valuable and capable of laying a foundation of data for researchers, criminal justice actors, lawmakers, and activists.

Total, there are 19,464 cases in AARDAS. However, not every case report is complete. As can be seen in Table 1, the data reveal that animal abuse cases were reported with increasing frequency every year from 2000 until 2006, at which point there was a brief decline until 2009. There was then a spike in the number of reports in 2010 followed by a drastic decline. Although this information is certainly beneficial, these data depict Americans' tendency to report animal abuse and not the number of actual abuses against animals. Neglect/Abandonment was by far the most common form of abuse with 5,591 different offenses being classified as such, making up approximately $32 \%$ of the total classifications. Hoarding, shooting, fighting, and beating were also methods frequently employed by abusers. The other 17 categories of abuse can be found in Table 2. Non-pit-bull dogs were the most common victims, comprising $41 \%$ of abused 


\section{Table 1}

Reported Animal Abuse Cases by Year, 2000-2015

\begin{tabular}{cccc} 
Year & Cases $(N=18,214)$ & Year & Cases $(N=18,214)$ \\
\hline $\mathbf{2 0 0 0}$ & 485 & $\mathbf{2 0 0 8}$ & 1,909 \\
$\mathbf{2 0 0 1}$ & 611 & $\mathbf{2 0 0 9}$ & 1,019 \\
$\mathbf{2 0 0 2}$ & 772 & $\mathbf{2 0 1 0}$ & 1,246 \\
$\mathbf{2 0 0 3}$ & 1,048 & $\mathbf{2 0 1 1}$ & 1,666 \\
$\mathbf{2 0 0 4}$ & 1,389 & $\mathbf{2 0 1 2}$ & 608 \\
$\mathbf{2 0 0 5}$ & 2,328 & $\mathbf{2 0 1 3}$ & 147 \\
$\mathbf{2 0 0 6}$ & 2,714 & $\mathbf{2 0 1 4}$ & 83 \\
$\mathbf{2 0 0 7}$ & 2,174 & $\mathbf{2 0 1 5}$ & 15 \\
\hline
\end{tabular}

animals in AARDAS. Cats, pit-bull dogs, and horses were also victimized more frequently than the remaining types of animals found in Table 3. Gender was known for 14,399 abusers of which 10,787 (75\%) were male and 3,521 (25\%) were female. For all types of abuse excluding hoarding, males were significantly more likely than females to commit the abuse. Abusers were generally older, with the $31-40$ age group having the most offenders. According to the data in AARDAS, the likelihood that an individual will abuse an animal increases until they reach the

\section{Table 2}

Abuse Classifications

\begin{tabular}{lcr} 
Type of Abuse & Classifications $(N=17,282)$ & Percent* $^{*}$ \\
\hline Neglect/Abandonment & 5,591 & 32.4 \\
Hoarding & 2,148 & 12.4 \\
Shooting & 1,956 & 11.3 \\
Fighting & 1,506 & 8.7 \\
Beating & 1,209 & 7.0 \\
Mutilation/Torture & 956 & 5.5 \\
Throwing & 436 & 2.5 \\
Stabbing & 432 & 2.5 \\
Burning - Fire or Fireworks & 365 & 2.1 \\
Unclassified & 315 & 1.8 \\
Vehicular & 307 & 1.8 \\
Poisoning & 305 & 1.8 \\
Kicking/Stomping & 245 & 1.4 \\
Choking/Strangulation/Suffocation & 243 & 1.4 \\
Bestiality & 229 & 1.3 \\
Unlawful Trade/Smuggling & 203 & 1.2 \\
Theft & 195 & 1.1 \\
Other & 163 & 0.9 \\
Unlawful Trapping/Hunting & 136 & 0.8 \\
Hanging & 125 & 0.7 \\
Drowning & 118 & 0.7 \\
Burning - Caustic Substance & 99 & 0.6 \\
*Rounded to the tenths place & \\
\end{tabular}

*Rounded to the tenths place 


\begin{tabular}{lcr}
\hline Table 3 & & \\
Animals in Abuse Cases & & \\
\hline & & Percent $^{*}$ \\
Type of Animal & 8,494 & 41.0 \\
Dog (non-pit-bull) & 3,384 & 16.3 \\
Cat & 2,466 & 11.9 \\
Dog (pit-bull) & 1,643 & 7.9 \\
Horse & 779 & 3.7 \\
Chicken & 386 & 1.8 \\
Bird (pet) & 377 & 1.8 \\
Cow & 373 & 1.8 \\
Rabbit (pet) & 354 & 1.7 \\
Goat & 345 & 1.6 \\
Rodent/Small Mammal (pet) & 316 & 1.5 \\
Reptile & 294 & 1.4 \\
Bird (wildlife) & 241 & 1.1 \\
Pig & 231 & 1.1 \\
Captive Exotic & 195 & 0.9 \\
Other Farm Animal & 172 & 0.8 \\
Other Wildlife & 134 & 0.6 \\
Bird (other farmed) & 131 & 0.6 \\
Sheep & 89 & 0.4 \\
Deer & 63 & 0.3 \\
Marine Animal (pet) & 60 & 0.2 \\
Raccoon & 34 & 0.1 \\
Rabbit (wildlife) & 34 & 0.1 \\
Squirrel & 30 & 0.1 \\
Opossum & 28 & 0.1 \\
Marine Animal (wild) & 25 & 0.1 \\
Other Companion Animal & &
\end{tabular}

*Rounded to the tenths place

31- 40 age range, at which point the likelihood begins to decrease. It is interesting to note that more than $60 \%$ of abusers were older than 30 years of age, which can be found in Table 4 . In cases where ownership of the victim was known, the owner of the animal victim was the abuser nearly two-thirds $(63 \%)$ of the time. Neighbors and owners of animals most commonly reported instances of animal abuse. Table 5 contains information regarding all other reporting parties. To summarize, patterns of abuse are inconsistent over time; non-pit-bull dogs were the most common victims, and neglect/abandonment was the most frequently employed form of abuse; males are far more likely than females to abuse animals, and offenders were generally older; and, abusive incidents were most likely reported by neighbors. 


\section{Table 4}

Age of Offenders

\begin{tabular}{cccc}
\hline Age Group & Abusers $(N=14,358)$ & Age Group & Abusers $(N=14,358)$ \\
\hline Under 10 & 53 & $\mathbf{2 6}-\mathbf{3 0}$ & 1,648 \\
$\mathbf{1 0}-\mathbf{1 4}$ & 273 & $\mathbf{3 1}-\mathbf{4 0}$ & 2,902 \\
$\mathbf{1 5}-\mathbf{1 7}$ & 595 & $\mathbf{4 1}-\mathbf{5 0}$ & 2,721 \\
$\mathbf{1 8}-\mathbf{2 0}$ & 1,274 & $\mathbf{5 1}-\mathbf{6 0}$ & 1,807 \\
$\mathbf{2 1}-\mathbf{2 5}$ & 1,800 & $\mathbf{6 1 +}$ & 1,285 \\
\hline
\end{tabular}

\section{Table 5}

Parties Reporting Animal Abuse

\begin{tabular}{cccc}
\hline Reporting Party & Cases $(N=8,662)$ & Reporting Party & Cases $(N=8,662)$ \\
\hline Neighbor & 3,200 & Relative & 106 \\
Owner & 1,208 & Customer & 71 \\
Other & 944 & Veterinarian & 71 \\
Unknown & 880 & Utility/Civil Worker & 53 \\
Police & 798 & Firefighter & 31 \\
Anonymous & 598 & Social Services & 21 \\
Partner & 247 & Friend & 20 \\
Shelter & 213 & Abuser & 13 \\
ACO & 177 & School & 11 \\
\hline
\end{tabular}

\section{Offenders}

Unfortunately, it is difficult to know who is committing animal abuse and exactly how frequently it occurs. The cases reported on Petabuse.com (2016) depict an older offender, which differs from past research. Vaughn et al. (2009) examined the rate of self-reported animal abuse among 43,093 participants of the 2001 - 2002 National Epidemiologic Survey on Alcohol and Related Conditions to help create an image of the average offender. Just fewer than $2 \%$ of respondents reported that they had committed animal abuse, which was measured by answering affirmatively to a single question that asked whether they had ever purposely been cruel to an animal in their life. Vaughn et al. (2009) found that animal abusers were more likely to be male and have lower levels of income and education. This finding has also been found by virtually every study examining animal abuse and gender. Flynn (1999) found that males are four times 
more likely than females to abuse animals. To be sure, women are more likely to be the perpetrators in instances of hoarding; however, male offenders outnumber female offenders in all other categories of abuse (Pet-abuse.com, 2016). Abusers were also more likely to be African American, Asian, or Native American but less likely to be Hispanic/Latino (Vaughn et al., 2009). Younger respondents reported animal abuse at a higher rate, which contradicts the statistics found on Petabuse.com. Those who have been married at some point in time, whether they were still married or widowed/separated, were more likely to abuse animals. Residents living in the West, as opposed to the other regions in America, reported abusing animals at a higher rate. Antisocial behaviors were more common among those respondents who admitted to animal abuse than those who did not. The incidence of psychiatric disorders characterized by low selfcontrol (e.g., lifetime alcohol use disorder, pathological gambling, conduct disorder and antisocial personality disorder) and personality disorders (e.g., obsessive-compulsive, paranoid, and histrionic) was also higher among individuals reporting animal abuse. Kavanagh, Signal, and Taylor (2013) found that psychopathy was the only variable that distinguished participants who had killed a wild animal and those that had not.

Research has indicated that incarcerated populations in general have higher rates of animal abuse when compared to the public (see generally Haden \& Scarpa, 2005). Miller \& Knutson (1997) found that $63 \%$ of the incarcerated sample $(\mathrm{N}=299)$ had abused animals while $20 \%$ of the undergraduate college student sample $(\mathrm{N}=308)$ had abused animals. To note, male inmates and male college students had been exposed to, as a witness to or perpetrator of, animal cruelty at relatively similar rates. Slightly more than two-thirds of each sample had been exposed to animal cruelty, indicating that exposure to the cruelty to animals is widespread among males. The two samples of females included in this study differed significantly in their 
exposure to animal cruelty. Roughly two-thirds of the female inmates had been exposed to animal cruelty, similar to male inmates and students, but only one-third of the female undergraduate students had been exposed to it.

While exposure to animal cruelty was around $50 \%$ for college males and females in Miller and Knutson's (1997) study, only one out of every five of the college student participants committed animal cruelty. Flynn (1999) found that one out of every six of his college student participants had committed animal cruelty, and that rate dropped to one in three when females were removed from the sample. Henry (2004) found that approximately 18\% (30) of his college student sample had committed at least one act of animal cruelty. These rates differ tremendously from Vaughn et al.'s (2009) finding that less than $2 \%$ of participants reported committing animal abuse. Given that animal abuse usually goes unreported because of its secret nature, a scale for detecting the propensity to commit animal cruelty would be useful. Alleyne, Tilston, Parfitt, and Butcher (2015) constructed the Animal Abuse Proclivity Scale (AAPS), which measures interest in committing animal abuse. The test-retest reliability of the scale was high $(r=.90)$, and it had cross-national validity. Additionally, the scale was significantly related to attitudes supportive of the mistreatment of animals and low levels of empathy. Their most important finding was, “[r]oughly $20 \%$ of female participants and $40 \%$ of male participants indicated some endorsement of behavioral propensity for the direct and indirect animal abuse scenarios..." (Alleyne et al., 2015, p. 582). Those percentages almost certainly included individuals who abuse animals but who do not report it, as well as individuals who possess the propensity to harm animals, but who refrain from acting. Being able to identify either group is beneficial.

Arluke (2012) conducted interviews with 25 college students who, as a child, had witnessed, but not participated in, animal abuse. He found that all were upset with having 
witnessed the abuse, but only five of them had intervened, and none of them reported the abuse to an adult. The consensus among the interviewees was that they thought the abuse was "dirty play" and something that children just did, especially boys. Most of them felt ill-equipped to intervene and confused about what to do in the situation. Additionally, they were afraid of losing their friends and being labeled a tattletale. Although none of the students participated in the abuse, they felt as if they were participants because they served as an audience for abusers who might not have harmed animals had no one been watching.

\section{Animal Abuse Statutes}

Every state in the U.S. has laws protecting animals. Generally speaking, animal protection laws suffer from the definitional issue that plagues academic definitions of animal abuse. There is no consensus on what constitutes animal abuse, and, as a result, state laws vary widely. While some states' laws offer better protections for animals than others (see ALDF, 2015), they are all generally composed of six elements: "1. the types of animals protected; 2 . the types of acts prohibited or duties of care required; 3 . the mental culpability required to meet a standard of liability; 4. the defenses to criminal liability; 5. certain activities exempted from the law; and 6. penalties for each offense" (Arkow \& Lockwood, 2013).

The first element, the types of animals protected, is especially important, but, as previously discussed, it has been difficult for jurisdictions to define what an animal is. Arkansas' and Mississippi's animal protection laws protect “every living creature;" while Texas' law only protects domesticated animals and wild animals previously captured; and, West Virginia's law fails to provide any description of what an animal is (Arkow \& Lockwood, 2013, p. 18). Such definitions are double-edged swords. When the definition is vague or nonexistent, such as West Virginia's, prosecutors might be able to charge offenders more frequently because 
the protections are not limited to specific types of animals, yet such vague definitions might prevent prosecutors from charging an offender because they are unable to prove that the victim should have been protected under the law. The types of acts prohibited or duties of care required, the mental culpability required to meet a standard of liability, and the defenses to criminal liability, which are the second, third, and fourth elements, respectively, are closely related and often combined to weaken the protection of animals. As previously mentioned, neglect is the most common form of animal abuse. While neglect of an owned animal is illegal, it is often difficult for the criminal justice system to intervene in instances of neglect. Generally speaking, animal protection laws require that malicious intent be proved and neglect is not typically the result of malice, and the acts often go unpunished. Additionally, hoarding is not illegal but usually constitutes neglect, which is. In hoarding cases, a mental health evaluation and treatment are often preferred over prosecution and punishment as mental illness may be the root cause.

The fifth element, the activities exempted from law, commonly found in animal protection laws is the most harmful element and severely weakens the laws. Political and public pressures are often enough to convince state legislatures to form or change animal protection laws to benefit them, especially their financial interests. For example, Pennsylvania, Missouri, and Texas all passed legislation in response to public outcry over puppy mills. Pennsylvania enacted one of the strictest dog breeding laws in the nation and acted on it, shutting down one of the biggest offenders within six months of enacting the law (Eisenstein, 2013). The laws that Texas enacted frustrated the public because they believed the standards were too weak and unable to properly combat the problem (Eisenstein, 2013). In Missouri, a puppy mill haven, an act was passed that would have considerably changed the lives of the dogs in puppy mills for the 
better; however, the state legislature ultimately gave into pressure from commercial breeders and those that support them (Eisenstein, 2013). The law was repealed and replaced with a much weaker one, which the governor believed to be a compromise that appealed to both animal rights activists and those that operated the puppy mills (Navarro \& Schneider, 2013). Ag-gag laws have recently been on the rise since the passage of such laws in Iowa in 2012 (Brewster \& Grugan, 2013). There are also exemptions from animal protection laws, like Alabama's law that allows for an individual to shoot a dog or cat with a BB gun for urinating or defecating on their property.

Statutes preventing animal abuse have evolved considerably throughout U.S. history, especially within the last decade; however, there remains room for improvement. As early as 1641, the Massachusetts Bay Colony included language in their "Body of Liberties" that protected animals from cruelty committed by humans (Livingston, 2001). This law, and most other early anti-cruelty statutes, was not concerned with protecting animals from suffering. Instead, these laws were merely put into place to protect animals because they were considered a person's property. Humans had extensively relied on animals to help with manual labor in the past, and, as such, there was an interest in protecting those "tools." It was not until 1866 that animals received protection for more than just their commercial value. During that year, Henry Bergh passed anti-cruelty legislation and founded the American Society for the Prevention of Cruelty to Animals (ASPCA) to help enforce the legislation (Farve, 2013). His 1866 legislation served as a stepping stone for getting the monumental 1867 New York Anti-Cruelty Law passed, which changed the way animal protection statutes were written (Farve, 2013). The law prohibited "unnecessarily" and "needlessly" beating, mutilating, killing, and other harmful actions (Farve, 2013). It also outlawed animal fighting. The law required animal owners to 
provide "sufficient" food and water, and penalized those that abandoned their infirm animals. Other features of the law included language detailing when arrests could be made for violations and various other protections for animals. Over the next 25 years, many states around the country began to pass similar anti-cruelty laws (Farve, 2013).

Nearly three decades ago, animal cruelty was only a misdemeanor that was punishable by a fine and no more than one-year imprisonment in 46 of the 50 states (Sherry, 1994). In 2004, the Humane Society of the United States reported that 41 states had felony animal cruelty laws (as cited in Allen, 2005). Fast-forward to March 14, 2014, and South Dakota becomes the $50^{\text {th }}$ state to pass legislation allowing for felony animal cruelty charges (Berry, 2014). While animals are still viewed as property in the eyes of the law as judges continue to abide by century-old precedents, it appears that this could soon change. In 2012, the Oregon Court of Appeals ruled that animals are more than just property and can be viewed as individual victims of crime (Wright, 2012). It is important to note, however, that this ruling was vacated. The Oregon Supreme Court did not vacate the ruling because of a disagreement with the Court of Appeals, but rather they vacated the ruling because the appellate court did not have jurisdiction (Wright, 2015). The Animal Legal Defense Fund (ALDF) reported in their 2015 U.S. Animal Protection Laws Ranking that Ohio became the $29^{\text {th }}$ state to extend the protection of protective orders to animals, further challenging the long-standing animals-as-property precedent. That same report also indicates that three-quarters of all states have strengthened their animal protection laws significantly over the past five years (ALDF, 2015).

Pro-animal organizations have been partially responsible for the evolution of animal protection laws. The Humane Society of the United States (2002) focused its attention on state legislatures in the 1990s in an attempt to persuade them to adopt felony animal cruelty legislation 
(as cited in Allen, 2005). Allen (2005) found that when a state's Humane Society member population increased, so did the likelihood that they would adopt felony animal cruelty legislation. However, the researcher was unable to find a relationship between Humane Society membership and the severity of the laws. Kordzek (2007) also found that states with a higher percentage of individuals associated with pro-animal groups were more likely to have adopted felony animal cruelty legislation and rank higher on ALDF's annual animal protection laws report, and less likely to require that an animal abuser have multiple convictions prior to being charged with a felony. She also found that conservative states, when compared to liberal states, were less likely to have passed felony statutes for animal abuse, less likely to require multiple convictions prior to felony charges, more likely to have sentences that were less severe, and more likely to rank lower on ALDF's annual report. These findings are a reflection of laws representing the morals of communities. Kordzek's (2007) finding of less severe sentences in conservative states lends support to Allen's (2005) finding that states with larger farming communities, which tend to subscribe to a conservative political ideology, are significantly more likely to have less severe sentences for animal abuse. In sum, animals have greater protections under the law today than they had ten years ago, but there is still much room for improvement.

\section{The Link between Animal Abuse and Subsequent Interpersonal Violence}

The clear majority of research on animal abuse is not concerned with the effect that the abuse has on the animals. Researchers have focused their attention on the link between abusing animals during childhood and subsequent offending as an adult. Specifically, researchers want to know whether animal abuse is predictive of interpersonal violence. Interest in this relationship began in the 1960s, and many contemporary researchers continue to examine the 
relationship (McDonald, 2011). Interviews conducted by Felthous and Kellert (1986) revealed eight common motivations for animal abuse:

- The use of animal abuse as extreme discipline.

- To satisfy a prejudice against a breed or species of animals (hatred of squirrels, cats, etc.)

- To express aggression though an animal, for example, inflicting pain to create an angry or mean animal.

- To enhance one's own aggressiveness, like using an animal for target practice.

- To shock others.

- To retaliate or take revenge against others (hurting pets or abusing animals in their presence).

- Displacement of hostility, whereby one attacks an animal since hurting a human is too risky.

- To experience specific or nonspecific sadism and enjoy the suffering experienced by the animal and the ripple effect to people, if applicable (as cited in Grant et al., 2015, p. 3).

While those motivations were discovered through interviews with adult males, animal cruelty often begins in childhood. A survey of 131 Australian youths revealed, "[c]ruelty to animals may have potential as an early indicator of trait factors placing children at risk for the development of ongoing problems" (Dadds, Whiting, \& Hawes, 2006, p. 426). The youths who had been cruel to animals had a more difficult time "[learning] adequate empathetic, consciencedriven behavior" (Dadds et al., 2006, p. 423).

The failure to develop empathetic, conscience-driven behavior has the potential to create a pathway for the child to commit violence as an adult. Hensley and Tallichet (2005b) examined the effect that childhood experiences and demographics had on the age at which an incarcerated sample first committed animal abuse and how frequently they did so. The age at which respondents first witnessed someone hurt or kill an animal significantly affected the age at which the respondent first hurt or killed an animal (Hensley \& Tallichet, 2005b). Specifically, those that had first witnessed animal cruelty at a younger age were more likely to have first committed it at a younger age. The age at which respondents first witnessed animal cruelty and witnessing a 
friend commit animal cruelty significantly affected the number of times they had hurt or killed an animal (Hensley \& Tallichet, 2005b). Thompson and Gullone (2006) found that the college students they surveyed were far more likely to have witnessed a stranger commit animal cruelty than a friend, relative, parent, or sibling; however, those that had witnessed a friend, relative, parent, or sibling commit animal cruelty reported significantly higher levels of animal cruelty. These findings suggest that, to an extent, animal abuse is a learned behavior, and that individuals are more likely to imitate their significant others. Volant, Johnson, Gullone, and Coleman's (2008) findings lend support to the notion that animal abuse is a learned behavior. In comparing a group of women who had experienced domestic violence with a group of women who had not, they found that, of the children in the domestic violence group, nearly one-third had witnessed their pet being abused, and almost one in five went on to abuse their own pets. In the group that had not experienced domestic violence, none of the children had witnessed animal abuse at the hands of their mothers' partners, and only one of them had committed it.

Tallichet, Hensley, and Singer (2006) examined how situational factors and demographics related to the methods of abuse a sample of inmates employed during their youth. They discovered that shooting was the most common method of abuse (64.3\%). They also found that whites and those who grew up in rural areas, were not upset with the animal abuse, had committed multiple acts of animal abuse, did not try to conceal the abuse, and had not acted alone were more likely to shoot an animal (Tallichet et al., 2006). It is possible that shooting was the most common method because it does not require the abuser to come into physical contact with their victim, making the act less intimate. Hensley and Tallichet (2005a) also examined how demographics and situational factors influenced the motivations to commit animal abuse among a sample of inmates. They found that approximately $42 \%$ of their sample 
had abused an animal. Of the 112 inmates that had abused an animal, nearly half (48.2\%) had done so out of anger; just over one-third (38.4\%) abused an animal for fun; approximately one out of five participants $(22.3 \%)$ did so because they disliked the animal, to control the animal $(22.3 \%)$, or out of fear of the animal $(21.4 \%) ; 15.2 \%$ abused an animal to imitate another person; $14.3 \%$ did so to seek revenge against another human and to gain sexual pleasure; approximately $10 \%$ wanted to impress someone, and nearly 5\% wanted to shock others (Hensley \& Tallichet, 2005a). Respondents who had acted alone were seven times more likely to have abused an animal out of anger. They also found that those who had acted out of anger were more likely to have done so to seek revenge on another person. This finding is unsurprising considering that animal abuse is often used as a means of interpersonal violence among domestic abusers.

The first known case report that linked domestic violence and animal abuse was released in 1806 and discussed a man who was violent to both humans and animals (as cited in Volant et al., 2008). Since then, the topic has received considerable attention. There are a few forms of animal abuse that are specific to domestic violence (Arkow, 2014). Abusers can emotionally abuse or intimidate and isolate the pet. They can minimize, deny, or blame the abuse on their victim. Victims can be legally abused if the abuser files a report for a stolen pet when they leave the relationship with the pet. Victims can also suffer economic abuse if the abuser prevents them from spending any money on the pet. Finally, abusers may abuse animals to intimidate their children or blame the harm the animal experienced on their partner to drive a wedge between them and the children.

Arkow (2014) reports that up to $71 \%$ of survivors of domestic violence have reported that their abuser abused their pet, by killing, hurting, or threatening it, to display their authority. There are several explanations as to why domestic abusers frequently target family pets. The 
simplest reason for it is because they can (Arkow, 2014). Pets are conveniently located within the home and cannot defend themselves, and abusing them is an effective method of control. Some abusers have reported that they hurt their partners' pets because they believed that doing so was not likely to draw the attention of law enforcement (Arkow, 2014). Other explanations include: it instills fear; it notifies all parties in the home that there will be no tolerance for misbehavior; and, it is done because the abuser is jealous of the attention their partner gives to the pet (Arkow, 2014). Once the victim of interpersonal violence leaves the abusive environment, the abuser can either punish them or convince them to return by continuing to threaten or abuse their pet.

Volant et al. (2008) compared rates of animal abuse among women who were survivors of domestic abuse and women who had never experienced domestic violence. They found that just over half of the women that had experienced domestic abuse had their pet abused by their partner, while none of the women in the other group had their pet harmed. Additionally, slightly less than half (46\%) of the women in the domestic violence group reported that their partner had threatened their pet, while only approximately $6 \%$ of the women who had not experienced domestic violence reported that their partner threatened their pet. Volant et al. (2008) also found that one-third of the women that were residing in a shelter for battered women had delayed their departure from the abusive situation because they were worried about their pet's wellbeing. Most them had delayed their departure for longer than two months. This finding has major implications for domestic violence shelter administrators who should consider accepting pets or working closely with local animal shelters to house pets.

Donley, Patronek, and Luke (1999) found that more than two-thirds (69.1\%) of the veterinarians they surveyed did not believe that animal protection groups have overplayed the 
connection between animal abuse and family violence. Half $(51.8 \%)$ of the veterinarians claimed to have seen clients they thought were being abused, and $15.5 \%$ of them claimed to have seen more than five clients they believed were being abused. That said, an overwhelming majority of veterinarians $(86.4 \%)$ reported that they would feel uncomfortable with asking their human clients about physical abuse they had personally experienced.

Childhood animal abuse is also commonly attributed as a precursor to acts of serious violence against humans, especially school shootings. Arluke and Madfis (2014) examined the 23 perpetrators of mass school shootings that occurred between 1988 and 2012 and found that only 10 of them had known histories of animal cruelty. These results beg the question of how robust the link between childhood animal abuse and extreme acts of violence truly is. Arluke and Madfis (2014) suggest that subsequent acts of violence can be predicted with greater certainty with specific types of animal abuse. Specifically, they claim that the torture of animals, especially dogs and cats (i.e. animals that have been anthropomorphized), in a hands-on manner may be a better predictor of subsequent acts of extreme violence than simply animal abuse in general.

This discussion of the link between animal abuse and interpersonal violence is by no means comprehensive, and it is not intended to be. Such a discussion is beyond the scope of this research.

\section{Theoretical Framework}

Fitzgerald, Stevenson, and Verbora (2013) outlined the theoretical frameworks that attempt to explain animal abuse. The study of animal abuse has expanded rapidly over the last two decades, but they chose to focus on nine theories to help illustrate the problem of animal abuse. The theories they cover include social learning, frustration and strain, differential 
coercion, violence graduation hypothesis (VGH), generality of deviance hypothesis, feminism, masculinities, (eco)Marxism, and cultural spillover. The VGH is the one of the oldest and most well-known theories of animal abuse. The theory states that individuals begin hurting animals in their youth and then "graduate" to violence against humans. There are two key elements of this theory: temporal and correlational (Fitzgerald et al., 2013). The temporal element requires that individuals commit animal abuse prior to committing violence against humans. The correlational element requires that individuals who abuse animals be more likely to use violence against humans than individuals who do not abuse animals. Abusing animals at a young age "provides the individual with the opportunity to learn first-hand about violence, practice violence on available targets (animals), and be desensitized to the consequences of violent behavior" (Walters, 2013, p. 797). While some argue that there is "striking support" for the VGH (Fitzgerald et al., 2013, p. 291), others argue that support for the VGH is based on anecdotal evidence (Walters, 2013). Walters (2013) points out that there have been numerous individuals that have carried out serious violent acts that did not have a history of childhood animal abuse. Two meta-analyses on the VGH failed to find support for the correlational element (Walters, 2013). The analyses found that, at least in males, abusing animals during childhood does not specifically lead to subsequent interpersonal violence. There was one female sample that suggested the correlational element might possess greater validity among females than males. Walters (2013) states that, while it may be premature to discredit the VGH entirely, animal abuse may be better defined as a correlate of offending behavior and indicator of general deviance than a stand-alone predictor of subsequent interpersonal violence.

The generality of deviance hypothesis has typically served as an alternative to the VGH (Fitzgerald et al., 2013). This hypothesis states that the abuse of animals is not specifically 
connected to interpersonal violence, but rather is a part of a spectrum of antisocial and criminal behavior. Animal abuse is believed to correlate with nonviolent offending just as much as it correlates with violent offending (Fitzgerald et al., 2013). It is also believed to be no more likely to precede violence against humans than it is to follow it. Arluke, Levin, Luke, and Ascione's (1999) finding that a group of animal abusers were more than three times as likely to have a criminal record that included violent, drug, and property offenses than a group that had not abused animals lends support to the generality of deviance hypothesis.

\section{Agnew's Theory of Animal Abuse}

Neither the VGH nor the generality of deviance hypothesis serve as an explanation for why individuals choose to abuse animals. Each theory explains that animal abusers are likely to move on to interpersonal violence or offending in general but not why they began abusing animals. In 1998, Robert Agnew developed a comprehensive theory of animal abuse.

Researchers have failed to thoroughly test Agnew's theory of animal abuse. It is comprised of validated theories of crime, including social learning, strain, control, and other theories. As mentioned above, the theory employed the following definition of animal abuse, "[a]ny act that contributes to the pain or death of an animal or that otherwise threatens the welfare of an animal" (Agnew, 1998, p. 179). He clarified that the "abuse may be physical (including sexual) or mental, may involve active maltreatment or passive neglect, may be direct or indirect, intentional or unintentional, socially approved or condemned, and/or necessary or unnecessary (however defined)" (p. 179). Also important to note is that the term "animal" referred to all non-human animals. Such a broad definition allows the theory to explain a range of abuses against all types of animals whether the acts were legal or illegal and whether society accepts or condemns them. 
The theory is composed of two parts. The first part includes the "individual factors that directly increase the propensity for animal abuse" (Agnew, 1998, p. 181). The three individual factors contributing to the likelihood that an individual will abuse an animal are the ignorance regarding the negative consequences that animals experience because of abuse, the belief that animal abuse is not wrong, and the belief that there is something to benefit from abusing animals (Agnew, 1998). People are often unaware of how their behavior affects animals because they are indirectly affecting them (Agnew, 1998). Additionally, many people are aware that their behavior affects animals, but they are unaware of the pain and suffering that it causes (Agnew, 1998). Therefore, much of the abuse that animals experience is the result of ignorance. Such ignorance results from participation in actions that pollute or destroy natural habitats, purchasing products that are either made of animals or were tested on animals, and participation in events that employ animals for entertainment purposes (Agnew, 1998). While most Americans believe that the abuse of animals is wrong, they also tend to believe it is justified when it benefits humans (Agnew, 1998). Abuse is frequently justified by believing the animal deserved it (i.e., the individual dislikes the animal), the abuse serves a higher purpose (i.e., medicinal testing or animal husbandry), animals would suffer more if not for the abuse (i.e., hunting serves as population control), and their behavior is not directly responsible for animal suffering (i.e., animals will be slaughtered for food regardless of whether they personally consume meat) (Agnew, 1998). Abusers also condemn those that condemn them, especially animal rights activists, when they partake in any activity that affects animals in the slightest. Sykes and Matza's (1957) techniques of neutralization or Bandura's (1990) process of moral disengagement can explain these justifications (Agnew, 1998). The third individual factor, much like the second factor, increases a person's propensity to abuse animals when they believe that 
the benefit of the abuse outweighs the cost (Agnew, 1998). It is important to note that, while an individual may possess the propensity to commit animal abuse, they will have difficulty doing so directly if they do not have access to any. Opportunities for indirect abuse (e.g., wearing fur, eating meat), however, are more widespread.

The second part of the theory includes "an additional set of factors that have both direct effects on animal abuse and indirect effects through the above three factors" (Agnew, 1998, p. 182). These factors include individual traits, socialization, strain, level of social control, the animal's nature, social position, gender, and other socio-demographic variables. Individual traits such as impulsivity, sensation-seeking, irritability, low self-control, and a lack of empathy affect the three major factors. These individual traits have all been shown to be conducive to crime. Individuals are socialized by the role models they encounter, the punishments and reinforcements they receive for their actions, and the beliefs that are taught to them (Agnew, 1998). Many Americans eat meat, so it is likely that any given role model does so. Additionally, using animal products is socially acceptable, and people are socialized from a young age to abuse animals, albeit indirectly. It is possible that companion animals socialize humans in a way that makes them sympathetic to the plight of animals. It is more probable that the individual would only be sympathetic to companion animals and not the animals being factory farmed (Agnew, 1998). Strain increases the likelihood that a person will commit animal abuse that is not considered socially acceptable (Agnew, 1998). Companion animals can create strain for their owners by attacking them or damaging their property. The individual experiencing strain might cope with their frustration by harming the source of it - the animal. Additionally, men who are not able to achieve masculinity through conventional means might abuse defenseless animals to assert dominance and appear powerful to alleviate the strain that results from their insecurities. 
Social control is measured by one's attachment to conventional others, their commitment to conventional institutions, and the level of supervision they experience by others. People do not want to disappoint their significant others, and they do not want to jeopardize their commitments to institutions that matter to them (e.g., work, school) by abusing animals (Agnew, 1998). If a person has a high level of social control, they are more likely to refrain from committing socially unacceptable acts of animal abuse. Social control should have no influence over socially acceptable acts because partaking in these acts will not threaten our relationships and commitments. An animal's position on the phylogenetic scale also contributes to the likelihood that an individual will abuse animals (Agnew, 1998). Humans are less apt to abuse animals that resemble them (e.g., chimpanzees), are cute (e.g., puppies, kittens), possess utility (e.g., horses), or carry historical significance (e.g., bald eagle). Social position, which includes gender, age, race, occupation, education, income, urban/rural location, and region, indirectly affect the likelihood that a person will abuse an animal through their individual traits, socialization, strain, and social control (Agnew, 1998). Women express greater empathy, affection, and moral consideration for animals; do not possess a strong desire to assert their dominance over animals; have less faith in science; and, generally subscribe to liberal and feminist ideologies (Agnew, 1998). Furthermore, women have been socialized to be more caring and nurturing, while males have been socialized to be dominant and aggressive.

Agnew's (1998) theory is comprehensive, but some variables are more relevant for certain types of abuse than for others. For instance, strain is one potential explanation for why individuals commit socially unacceptable forms of animal abuse. Ignorance is the most relevant variable for socially acceptable forms of animal abuse. 


\section{The Criminal Justice System's Response}

Agnew (1998) believed that "The extent and severity of animal abuse make it one of the leading problems of our time" (p. 203), but does the criminal justice system agree? As previously discussed, researchers have mainly been concerned with the implications that animal abuse has for humans, and the court system currently views animals as little more than property; however, this has begun to change as evidenced by an Oregon court ruling in 2012 (Wright, 2012). Beginning in 2016, the FBI began tracking animal cruelty as a separate offense in NIBRS (FBI, 2016), and the National Sheriff's Association has created the National Law Enforcement Center on Animal Abuse (NLECAA) (Akpan, 2014). NLECAA provides information on animal abuse and serves as a forum for law enforcement with the purpose of expanding law enforcement's knowledge of animal cruelty (Akpan, 2014). Not every law enforcement official believes that animal abuse is of great importance, however. Kentucky State Police (KSP) Captain Bob Murray stated, “"[w]e are pro animal, but, not that they're not worth our response

— they are — but you weigh the balance of, do we put our efforts toward the war on drugs or the less dominate cock/dog fighting?' Murray continued. '[n]ot to say that it's not going on and not serious because it is, but we get a lot fewer complaints in regard to those things.' (Darst, p. 23, 2011). Partially responsible for the limited complaints of animal fighting is local support for the activities. Whenever events were held at the previously titled Spring Brook Farm, a 700-seat arena for cockfighting the KSP raided in 2005, the local economy was stimulated with hotels, restaurants, and gas stations experiencing a sharp increase in business (Darst, 2011). This business was of great value to the town of only 2,000 residents; therefore, the community supported the events and refused to aid law enforcement in the detection of the operation. Support for cockfighting could be why the state's animal cruelty statute (KRS 525.125) only 
protects four-legged animals. The ALDF's 2015 U.S. Animal Protection Laws Ranking report has Kentucky ranked as the worst state for animal protection laws for the previous nine years.

Generally speaking, district attorneys' offices are forced to work with insufficient funds and staffing, which requires them to prioritize their cases. Unfortunately, animal cruelty cases often receive limited attention as a result. Violent crimes against humans usually take precedence because society holds humans in a higher regard than animals. Additionally, animals are not able to speak, so prosecutors must rely on the physical evidence, making prosecutions difficult to achieve. Furthermore, most animal abuse cases are the result of neglect, which many argue is not a result of malice, but rather ignorance. Couple all of this with ambiguous statutory language, and many prosecutors will determine that animal cruelty cases are not worth their time. Donely, Patronek, and Luke (1999) examined 200 randomly selected complaints that had been registered with the Massachusetts Society for the Prevention of Cruelty to Animals in 1996 and found that the law had been broken in 75 (37.5\%) of those cases, but only six resulted in prosecution. Some law enforcement agencies have begun vigorously pursuing cases of animal cruelty because they have become aware of the connection that exists between animal cruelty and other crimes such as domestic violence, child abuse, gambling, drug offenses, and illegal firearm offenses (Eisenstein, 2013). However, law enforcement frequently encounters the same issues as prosecuting teams including limited budgets, lean staffing, a reliance on physical evidence, and vague statutes.

To combat the issue of physical evidence, it has been suggested that veterinarians accompany law enforcement to crime scenes involving animals because they are better equipped with the training necessary to handle the physical evidence (Eisenstein, 2013). Donley et al. (1999) found that slightly more than one-third of the veterinarians they surveyed had been asked 
by police to examine an animal and/or its environment. To combat the issues of limited budgets and lean staffing, agencies investigating animal abuse can recruit the help of other agencies. In Wellington County, Ontario, Zilney and Zilney (2005) conducted an experiment in which Family and Children's Services (FCS) investigators and Humane Society (HS) investigators crossreported findings of animal and child abuse. Between February 1, 2001 and January 31, 2002, FCS and HS investigators were asked to complete checklists during home visits: FCS investigators made 16 referrals ( $2.1 \%$ of completed checklists), and HS investigators made ten referrals (10.6\% of completed checklists). The researchers found that some of the FCS investigators were hesitant to complete the checklists even when animal abuse was present. Regardless, the experiment undoubtedly strengthened the relationship between the two agencies, which can only serve to detect more cases of abuse.

\section{Veterinarians' Perception of Animal Mistreatment}

Donley et al. (1999) surveyed 110 veterinarians on their experiences with and attitudes and perceptions of animal mistreatment. Eighty-six veterinarians reported that they believed they had seen at least one injury to an animal caused by its caretaker, while only 18 of them believed they had seen it more than five times. Nearly half (47.3\%) of them were positive that the injuries they noticed were deliberate, but only one-third of them had a client admit to abusing their pet. Four out of every five veterinarians stated that they had witnessed animal abuse in their community. The clear majority (93.6\%) believed it was their ethical responsibility to report deliberate abuse and neglect, but less than half (44.5\%) believed that they should be legally required to report abuse, and only one-third believed that reporting neglect should be required. Around two-thirds (76.4\%) of the veterinarians did not feel that they knew where to draw the line between poor care and neglect. Seventy percent of them believed they would be more 
willing to report neglect if there was published criteria. Just over one-third of the participants felt they needed additional training in detecting abuse and neglect, but $84.5 \%$ believed that such training should be a part of veterinary education.

Of the 102 veterinarians who knew who to call to file a report of animal abuse, only 40 had made a report at the time of the survey. Eighty-five of them stated that they would be more likely to file a report if they had confidence in the investigating agency, and 81 stated they would file a report if they knew it would remain confidential. Forty-two veterinarians were worried about the repercussions of filing a report. Such repercussions included being sued by the suspected abuser for slander, being sued for violating the doctor-patient confidentiality privilege, and placing themselves and their employees at risk for being harmed by abusive clients. One veterinarian reported having been confronted by a client for reporting suspect animal abuse.

Donley et al.'s (1999) study did an excellent job of shedding light on how veterinarians perceive the reporting process. Unfortunately, their results found that, "[s]ome respondents were skeptical that legal intervention would improve conditions for the animal and expressed great frustration about the perceived inaction on the part of authorities or of being told that nothing could be done after a complaint was lodged" (p. 69). Clearly, veterinarians believe that more needs to be done by the criminal justice system in response to animal abuse. 


\section{CHAPTER III}

\section{METHODS}

\section{Purpose of Study}

As the literature review highlighted, the bulk of the research focused on animal abuse is concerned with the consequences that animal abuse has for humans. Specifically, researchers have been focused on learning whether abusing animals conditions the abuser to commit subsequent interpersonal violence. Virtually none of the animal abuse literature has focused on veterinarians or their perceptions of the criminal justice system's response to animal abuse. The researcher aimed to help close this gap in the literature by interviewing veterinarians about their experiences with animal abuse and the criminal justice system. Veterinarians are uniquely positioned in society to champion for a population that the criminal justice system has historically failed to protect. Understanding how they view the response to animal abuse and what they believe an appropriate response consists of is imperative to effectively combat the problem of animal abuse.

\section{Sample}

The researcher interviewed veterinarians about their experiences with animal abuse and the criminal justice system for the study. The only criterion for participation required that each participant was a doctor of veterinary medicine, and participation was entirely voluntary. Every veterinary clinic located in McLean County, Illinois, 17 in total, was contacted for participation in this study. Those 17 clinics employed a total of 39 veterinarians. Prior to any veterinary 
clinics being contacted, the researcher received approval to conduct the study from the Institutional Review Board at Illinois State University.

\section{Recruitment of Participants}

Participants were recruited by employing a convenience sampling method. The researcher contacted every veterinarian clinic located within McLean County, Illinois. Because the Animal Legal Defense Fund (ALDF) (2015) has ranked Illinois' animal protection laws as the strongest in the country for the previous eight years, the researcher was interested in knowing if this high praise was justified in practice. McLean County was selected as the research site because of its proximity to the researcher.

Each veterinary clinic was contacted by the researcher. Emails including a standard email letter (APPENDIX B) were sent to the clinics the researcher possessed an email address for. If the researcher did not have a clinic's email address or if the clinic did not respond to the email, the researcher called the clinic and read from a standard telephone script (APPENDIX B). All email addresses and telephone numbers obtained by the researcher were public information. With all participants, the purpose of the study was explained, and the individual was given the opportunity to view a copy of the interview guide prior to giving verbal consent to participate in the study. Once verbal consent was given, they were asked to schedule a date and time for the interview that was convenient for both their self and the researcher. Before every interview began, the interviewee was required to sign an informed consent form (Appendices $\mathrm{C} \& \mathrm{D}$ ) after they had read it over. Additionally, they were required to sign a form stating whether they consented to an audio recording of the interview. If, at any point, the participants decided they no longer wished to participate in the study, they were able to do so immediately and requested 
to sign a form (APPENDIX E) stating whether they allowed the researcher to use that data collected.

\section{Instrumentation}

The researcher conducted semi-structured interviews on a one-on-one basis with each participant. Interviews were conducted face-to-face unless the interviewee preferred to complete the interview via phone. An interview guide (APPENDIX A) was employed to ensure that all major themes were discussed, but each participant could speak freely about their experiences with animal abuse and the criminal justice system. The guide directed the researcher to begin each interview with the collection of demographic data including gender, race, and job title. Participants were also asked how long they had worked in their current position as well as how long they had worked with animals in general. Data on the number of years in practice were collected because Donley et al.'s (1999) survey of veterinarians found that older veterinarians differed significantly from younger veterinarians in their responses to questions concerning the reporting of animal abuse.

Once participant demographics were documented, the interview guide directed the researcher to discuss the first topic: experiences with animal abuse. Participants were first asked about their professional experience with animals. In doing this, the researcher could build rapport with participants, which is paramount to successful interviewing. Following this, participants were asked to describe their familiarity with animal abuse in their capacity as a veterinarian. Next, the veterinarians were asked about any training they had received in detecting animal abuse and what procedures they adhere to when handling and reporting it in their current position. It is possible that this information offers an explanation as to why some veterinarians report animal abuse whereas others do not. It also might help partially explain the 
perceptions that veterinarians have of the treatment of animal abuse cases in the criminal justice system. Finally, participants were asked about personal experiences with animal abuse they encountered in their capacity as a veterinarian during the preceding 18 months and how they handled it. Since the focus of this study is on the perception of the treatment of animal abuse cases in the criminal justice system, responses to this question were of great importance.

Participants who answered affirmatively to having personally experienced animal abuse while working as a veterinarian were then asked the questions pertaining to the second topic, interaction with the criminal justice system, if they had reported those incidents to the criminal justice system. The researcher asked each interviewee to elaborate on their experience in interacting with the criminal justice system. A person's experiences with the criminal justice system can influence their perceptions of the criminal justice system. Following this, they were asked to describe their involvement in the case and the outcome of the case. It is also possible that these aspects influence their perception of the criminal justice system. Finally, participants were asked to describe their perception of the treatment of animal abuse cases in the criminal justice system. All participants, whether they had reported animal abuse to the criminal justice system, were asked this question. Responses to this question were of the utmost importance as gathering knowledge of their perceptions was the main purpose of the study. The researcher believed that it was important to ask all participants to discuss their perceptions of the treatment of animal abuse cases in the criminal justice system to discern any differences between those who had experience with the criminal justice system and those that did not. Participants were also asked to discuss any changes they would like to see the criminal justice system make when handling animal abuse cases. 


\section{Analysis Plan}

With the participants' permission, all interviews were audio recorded so that the researcher could better analyze the data. Additionally, recording interviews meant that the researcher was not required to take notes during the interviews. Taking notes can damage the rapport between researcher and participant, as well as prevent interviews from transpiring organically. Notes were taken immediately following each interview, so that the researcher's thoughts and impressions were recorded while they were still fresh in the mind.

As soon as possible following each interview, the recordings were transcribed verbatim. Following transcription, the researcher listened to each recording while reading along with the transcripts to ensure accuracy. Following the transcription of each interview, an open-ended approach was employ in coding the data. Initially, responses were coded into two broad pre-set categories: professional experiences with animal abuse and interaction with the criminal justice system. Identified responses were then read multiple times until the research noticed recurring themes. These recurring themes were used to create coding key which helped identify more specific emergent categories. Analyzing the responses in the "professional experiences with animal abuse" category led to the creation of "familiarity with animal abuse" and "handling of

animal abuse" categories. Doing so with the "interaction with the criminal justice category" led to the creation of "involvement with the criminal justice system" and "perceptions of the criminal justice system's treatment of animal abuse cases" categories. Responses were then coded to be included in the most appropriate of the four specific categories. Relevant quotes were identified to exemplify each category and provide a voice for the participants (Padgett, 1998). No preconceived notions influenced the researcher at any point during the process as this study is meant to be purely exploratory. 


\section{CHAPTER IV}

\section{DATA ANALYSIS}

The purpose of this study was to explore veterinarians' experiences with animal abuse and their perceptions of the criminal justice system's treatment of animal abuse cases. To do so, the researcher conducted semi-structured interviews with veterinarians in McLean County, Illinois. Interview times ranged from 24 minutes to 56 minutes and averaged 42 minutes. Demographic data were collected so that the researcher could discern whether differences in responses were based on demographics, especially the number of years in practice. For a complete list of questions, see APPENDIX A. Following the transcription of each interview, transcripts were closely examined and recurring themes were identified. A category key was developed using common themes, and all themes and quotes were categorized in the appropriate category. Those themes were used to describe the participants' professional experiences with animal abuse and how they perceived the criminal justice system's response to animal abuse cases. Quotes are used to highlight those experiences and perceptions. In this chapter, the participants and their responses will be discussed.

\section{Overview of Sample}

In total, 17 clinics were solicited for participation in the current study. Those 17 clinics employed a total of 39 veterinarians. Of those 39 veterinarians, five agreed to participate in the study resulting in a response rate of $12.8 \%$. While there was a low number of participants in this study, the goal of the research was to explore the perceptions of this population. The researcher 
was able to glean in-depth information from the participants, which can prove to be valuable to researchers and practitioners in the field.

\section{Demographics}

Though the sample size was small, the sample shares many similar characteristics to those of veterinarians in McLean county. Of the 39 veterinarians in the county, 20 are female (51\%) and 19 are male (49\%). The American Veterinary Medical Association (n.d.) reported that $40.7 \%$ of veterinarians employed in $2016(107,995)$ were male and $59.1 \%$ are female, with the remaining $0.2 \%$ being unknown. Race was known for 35 veterinarians, and they were all white $(100 \%)$. As shown in Table 1, female participants only outnumbered male participants by one and all were white. Four of the veterinarians went to the same veterinary school. Their amount of experience varies considerably; however, all participants had significant experience working as a doctor of veterinary medicine. It is important to note that all participants were assigned a pseudonym to maintain confidentiality.

\section{Table 6}

Demographics

\begin{tabular}{lcclc}
\hline $\begin{array}{l}\text { Gender } \\
\text { Male }\end{array}$ & Frequency & $\begin{array}{c}\text { Percent } \\
40 \%\end{array}$ & Participant & $\begin{array}{c}\text { Veterinary } \\
\text { Experience (Years) }\end{array}$ \\
Female & 2 & $60 \%$ & Dr. Courtney Long & 10 \\
& 3 & & Dr. Lily Faulk & 13 \\
Race & Frequency & Percent & Dr. Stephanie Warner & 23 \\
White & 5 & $100 \%$ & Dr. Chris Quinn & 24 \\
Non-white & 0 & $0 \%$ & Dr. Justin Donald & 32 \\
\hline
\end{tabular}

\section{Professional Experiences with Animal Abuse}

The semi-structured interviews were guided by an interview guide (APPENDIX A) that ensured the researcher touched on two topics. Professional experiences with animal abuse was the first topic covered by the interviews, and it can be broken down into two recurring themes: (1) familiarity with animal abuse and (2) handling animal abuse. As discussed below, virtually 
all the participants' experience with animal abuse involved neglect as opposed to forms of physical abuse (e.g. stabbing, throwing, poisoning). Additionally, participants appear to be reluctant to involve the criminal justice system when they do encounter animal abuse. The following is a discussion of those themes.

\section{Familiarity with Animal Abuse}

To learn what the participants knew about animal abuse, they were asked to discuss their familiarity with animal abuse in their capacity as a veterinarian. It was important to gather a baseline for their knowledge of animal abuse as their awareness influences their perception.

Neglect. While discussing their familiarity with animal abuse, every single participant specifically mentioned neglect, and three of them stated that neglect was the form of abuse they encountered most frequently. The majority of time spent discussing abuse with the participants was spent discussing neglect. Dr. Justin Donald, who not only had the most experience in private practice but also over a decade's worth of experience volunteering his services to animal rescue networks, estimated that $80-90 \%$ of the abuse he has encountered has been neglect. Whether that estimation is representative of animal abuse as it occurs is up for debate. Dr. Chris Quinn also stated that neglect is the form of abuse presented to him with the greatest frequency; however, he is not convinced that is because it occurs more frequently than physical abuse. He believes that neglect is easier to document than physical abuse, which is why it appears to happen with a greater frequency. Neglect, according to Dr. Quinn, is easier for veterinarians to detect because the animals are typically left outside without proper care, and neighbors can see and report it. Additionally, these animals are often presented in such poor physical condition, which is easier to detect than an animal who has been kicked or thrown. Dr. Courtney Long stated that "there's a fine line between abuse and neglect" and that she was thankful that she 
encountered neglect more frequently than physical abuse, presumably because she felt that physical abuse was more heinous than neglect. Drs. Lily Faulk and Donald were frustrated with the lack of legal definitions that clearly defined what was and was not considered abuse. Regarding neglect, Dr. Faulk questioned whether an action had to be intentional to be classified as abuse. She stated that some people believe animals do not feel pain or they believe animals possess an extremely high tolerance for pain and, as such, fail to provide proper care for their pets, thus neglecting them. "Is that abuse," she wondered. It was pointed out by Dr. Quinn that acts of neglect fall on a spectrum from less severe and unintentional to more severe and intentional, whereas, regarding physical abuse, you either hit your pet or you do not hit your pet. As he put it,

You can't fail to realize you're beatin' the shit out of your dog, but you can fail to realize that you're not taking care of an animal the way you should.

In a sense, Dr. Donald rationalized the actions of some, but not all, of those who neglect their pets. Most of the abused animals he encounters are either very young (i.e. puppies) or geriatric because the standard of care is much more demanding, and many such pet owners do not realize this or cannot provide the necessary care. He asserted that most people who neglect their pets do love them, but they lack the means to provide sufficient care. They are usually in poor shape themselves as their own standard of care is subpar. Dr. Donald exhibited sympathy when he questioned,

What do you do, take a homeless person who's not takin' good care his pet and take the dog from him? Not a chance. I mean, I can't do that. I mean, the poor guy'll probably jump off the bridge, you know?

He was not sympathetic towards all those who neglect and otherwise abuse their pets, and he believes that there is something wrong with people who choose to abuse animals. When 
explaining that animal abusers would never admit to a veterinarian that they abuse their pet, he stated,

[M]entally ill people that abuse their dogs are not gonna come and say, 'Yea, you know, I locked my dog in-in the closet for three days because it pooped on the floor.'

The researcher found it interesting that Dr. Donald would identify the abuser in this scenario as being mentally ill and interpreted it as him assuming a person must possess a mental deficiency to choose to abuse their pet.

Frequency. Though neglect was the most common form of abuse encountered, encountering it and other forms of abuse was far from common for these veterinarians in private practice. Four of the participants stated that animal abuse was rarely presented to them at their practice. Dr. Donald estimated that only a very small percentage of what he saw was abuse, pointing out,

[I]n general practice, most people come in with money...they are taking care of their animals. I would say in general practice, probably less than $5 \%$ of the time we see animals that are abused.

He pointed out that even if people abuse their pets, they would never admit to it, which makes his job more difficult. Dr. Quinn resonated this belief, saying,

If you're in a practice that's stable, solid, good healthcare, good animal care approaches, you don't see any abuse... I think we're several layers away from where the real crap's happening... we're pretty layered and insulated from being in the front lines of it.

However, again, he is not convinced that is because animal abuse just is not happening. He suggested that when animals are brought in with injuries, he "may miss the fact that the owners are the cause of the injury." One explanation he offered as to why animal abuse goes undetected is that he "may not be looking that hard" for it because veterinarians "get pretty battered emotionally," and he believes that "there's a voluntary stay-off-the-front-lines for a lot of 
veterinary populations." He discussed one of his children's interest in reality television shows depicting animal abuse, stating,

[S]he'll be tellin' me about it, and I'm like, 'I don't, you know, I saw some of that, I lived it, I don't need to stop and use my free time to go find stories of animals getting the shit kicked out of them,'so I try to avoid it like the plague when I have the choice.

Dr. Stephanie Warner also suggested that animal abuse is rarely encountered because veterinarians miss the signs, noting,

[W] could be seeing it and not knowing that we're seeing it. You know, the dog comes in limping, and they don't know what happened, or, you know, somebody stepped on the dog, and we don't really know if that's what happened or whether the dog was kicked or, you know, intentionally harmed. So, sometimes I'm sure we've seen things but didn't know we were seeing it.

She pointed out that she cannot think of any colleagues over the past 23 years that have been involved with an animal abuse case that went through the criminal justice system.

Animal abuse, in the participants' experiences, was much more common while working in animal shelters or emergency clinics. Dr. Donald stated that approximately $10 \%$ of the animals he encountered through working with animal shelters were victims of abuse. He clarified that the estimate is low because most of the animals were taken from other shelters that euthanize animals; therefore, the animals were receiving care but they were at risk of euthanasia. While working with an agency that took animals in directly, he believed that about half of all the animals were victims of animal abuse. Most of the abused animals he has cared for did not have an owner and were brought in for care by another party. Drs. Long and Faulk have both worked at an animal emergency clinic, and both reported that they encountered animal abuse with greater frequency there than in their regular practice. According to Dr. Long, about once a year or once every other year, the police would bring an abused animal to her at the emergency clinic in addition to all the other animals that are brought in. 


\section{Handling Animal Abuse}

After participants discussed their familiarity with animal abuse, they were asked to describe the procedures they adhere to when handling and/or reporting abuse or suspected abuse. The researcher was interested in knowing how veterinarians dealt with abuse or suspected abuse when they encountered it because it would give the researcher an idea of how likely they were to contact the criminal justice system. Donley et al. (1999) found the nearly four out of every five (78.9\%) veterinarians surveyed believed they were presented with an animal that had been the victim of abuse; however, only slightly more than one-third (36.4\%) of them had filed a report of abuse to law enforcement. Many $(77.3 \%)$ stated they would be more willing to file a report if they had confidence in the investigating agency or if they were certain that their report would remain confidential (73.6\%). Veterinarians in the state of Illinois must file a report to the Department of Agriculture every time they are presented with an animal that has been the victim of aggravated cruelty or torture pursuant to 510 ILCS 70/3.07. As the results will indicate, the veterinarians interviewed were more likely to opt out of reporting animal abuse, suspected or actual, presented to them than they were to file a report.

Procedures. When encountering abuse, Dr. Long documents every detail including why she suspects the animal had been abused and what led her to that suspicion. For Dr. Faulk, the most important course of action when encountering abuse is to educate the owner of the pet because most of the abuse she encounters in private practice is the result of ignorance. She claims to have offended a few people in doing so but urged the importance of ensuring that pet owners understand how to care for their pets. If they are still unable to provide proper care following education, she begins to question whether they should continue to own the pet. Drs. Donald and Quinn also stated that they attempt to educate the clients who fail to provide 
sufficient care for their pets. Dr. Donald described his method of confronting the owners who are neglecting their pets,

[W]e do confront them, and we do outline what we think minimal, acceptable care is, and we encourage them to respond, and we usually set up a re-check, a follow-up, but that's as far as we can go.

Dr. Quinn noted that veterinarians must be careful when confronting pet owners who provide unsatisfactory care because doing so could upset the individual and instigate further abuse. He used the example of child abusers to get his point across:

[Y]ou gotta be careful that you don't set off more abuse by finding it and not being able to do anything about it. You know, if you go to a parent and say, 'We think you're doing something bad to your kid,' they're gonna go home and beat their kid 'cause it's their kids fault for that, you know?

This led him to discuss the time his staff had confronted a man who transported his puppy to the clinic in the trunk of his vehicle. The man was upset and never came back. He genuinely wondered whether they helped that dog or if it was riding around in the trunk of the car somewhere. Dr. Warner also discussed the importance of being discreet; however, she was referring to the handling of instances where both the pet and the individual presenting the pet exhibit signs of abuse. For her, it is important to allow victim to come forward with the allegations of abuse on their own time, but she also mentioned the potential for a lawsuit if she were to incorrectly make those allegations as a justification for discretion.

Reporting. Interestingly, nearly every participant discussed reporting their suspicions of animal abuse to agencies external to the criminal justice system. Dr. Long spoke of cooperating with the humane investigators that worked for a local rescue network when she encountered abuse. She did mention that police officers have presented abuse to her; however, that relationship is not reciprocal. Before reporting abuse, she must be almost certain that the person 
has abused an animal because she does not want to accuse someone of doing something they did not do. When asked how confident she must be, she stated,

I don't want to accuse somebody of doing that, you know, something that they didn't do. So, if I was $80 \%$, I would be like, 'Ehh, it's weird. I suspect...' but I wouldn't pursue it, but if it was $90 \%$, even though I still had that $10 \%$ of not being sure, I would pursue it, and probably make a police report and, you know, see what channels to go by.

Her patients are given the benefit of the doubt, and she accepts their explanations for how their pet was injured at face-value since it is not uncommon for an animal to injure itself. If a patient of hers claims to know of an abused animal, she encourages them to report the abuse to that humane investigators she works with, but she does not act on that information because she is not confident in the average person's ability to properly assess a situation such as that. Drs. Faulk and Donald identified Animal Control as the agency they typically work with. Dr. Faulk noted that handling animal abuse is easier when Animal Control presents the abuse to her because they generally have already begun the process, and she is just required to provide care to the animal and her opinion to the agency. Dr. Donald pointed out that veterinarians are required to report animal abuse and that there would be repercussions should they not. He was the only participant to bring this up, and he brings all felony animal abuse to the attention of law enforcement. Unless she is in possession of definitive proof, Dr. Warner does not bring animal abuse to the attention of law enforcement. Instead, she chooses to bring abuse to the attention of the humane investigators at the Humane Society.

Training. Perhaps the most startling finding regarding how the participants handled animal abuse was that none of them had received official training throughout veterinary school nor from their employer. Donley et al. (1999) found that three-fourths (76.4\%) of their participants were unsure of where to draw the line between poor care and neglect, $70 \%$ would have been more likely to report neglect had there been published criteria outlining it, one-third 
$(34.5 \%)$ believed they required additional training to detect abuse and neglect, and the majority of them $(84.5 \%)$ believed that such training should be a requirement for veterinary education programs. Dr. Faulk referred to the lack of formal training as "crazy," and the only thing that Dr. Warner could say was, "There was nothing. There was no discussion. There was nothing.” Dr. Quinn also reported that he did not receive any training and stated that he believes that to be the case for most veterinarians. Dr. Long, who had completed veterinary school most recently, was taught to suspect abuse as a possible explanation for certain disease processes and to always suspect abuse when an animal was presented with trauma, but that was the extent of her training in detecting animal abuse. Dr. Donald has received training, but he admitted that it was not official training and was done voluntarily. Voluntary training is problematic to him because many veterinarians choose not to partake in it.

Incidents. Participants were also asked to discuss any instances of actual or suspected animal abuse they had encountered during the preceding 18 months and how they handled those incidents. Only one participant could identify a specific incident that had occurred during that time frame.

Dr. Faulk was the only participant that identified specific instances of animal abuse that she had encountered during the preceding year and a half; however, the criminal justice system was not involved in any of those instances. While working at an emergency clinic, she was presented with a kitten that had been thrown against a wall. A young boy, approximately five to nine years of age, was with friends when he threw a kitten against a wall.

She described the situation as so,

It was a kinda [an] outdoor [cat], cat had had kittens, and I think the family went to go feed the kittens and Mom, and they noticed one was missing. They went into the garage where the children were playing with the kittens, and found this one kind of stashed behind somewhere having problems, bleeding. 
When the animal was presented to the emergency clinic, the man that had brought the kitten informed her that the boy responsible for the injuries had a history of psychiatric problems. She provided care for the kitten, and though it ultimately survived, it was severely injured. As she put it,

[T]here was no doubt this animal was harmed. I mean, they had blood streaks on the walls and everything. They were just terrified.

The night of the incident, she decided against notifying law enforcement of the situation because the offender was a juvenile. She has a negative opinion of the juvenile justice system and did not believe there would have been repercussions for the child; however, she did say,

I think if this was an adult who had done this, I'd have no problem calling the police and discussing with them what I must be doing at that point.

The emergency clinic's office manager did call law enforcement the following day to ensure that something had been done, and the man who brought the kitten in notified the clinic that the boy had been admitted to a psychiatric facility. The following week, she was presented with a dog that had a hematoma on its head at the emergency clinic. A young girl, approximately eight to ten years of age, claimed that a mug had fallen on top of the dog's head, and that is how the dog was injured. Given the severity and placement of the injury, Dr. Faulk and the owner of the dog, the girl's aunt, were skeptical that this was the truth, and both believed the young girl intentionally hit the dog on the head. She provided care for the dog, and it survived. She decided against notifying law enforcement this time as well because, in addition to the offender being a juvenile, she did not have definitive proof that the girl intentionally harmed the dog. She did believe that this case was probably abuse, though, stating,

So, that was another suspicious case...I mean, I feel like that was probably animal abuse, but there was no way to prove it "cause nobody other than the child and the aunt was in the home. 
There was a third incident she discussed during the interview that had occurred approximately two years prior where a dog had been left in an abandoned house during a winter month. A neighboring county's Animal Control brought the dog to her, and she provided care for it; however, the dog had passed within two days. She was not involved with that case beyond providing care.

The other participants had identified instances of abuse they had encounter during the preceding 18 months and beyond, but specifics were not provided which makes it impossible to discuss. For instance, Dr. Long stated that there have been a handful of times that law enforcement brought a neglected animal to her at the emergency clinic, but she was unable to recall any details beyond the fact that she cared for those animals when they were presented. Dr. Donald estimated that in the preceding 18 months, he encountered ten instances of animal abuse but then later estimated that he probably sees one case of abuse per month at his general practice. No specifics were provided to clarify this conflicting information. Given the context, the researcher believes that Dr. Donald was stating that he has been a part of ten cases through rescue agencies in the previous year and a half, and that once a month he has a client bring in an animal that is not receiving proper care. Dr. Warner was able to provide minor details about two instances of animal abuse that had happened years prior. One involved a dog she referred to the Humane Society that she described as,

[O]nce I had a kid who put a rubber band on a cat's leg, and the mom didn't know it, and she brought it in several days later, and we found the rubber band, you know, embedded in the skin.

Another case involved a woman who not only had an abused dog but was abused herself:

[W]e had a woman once who brought her Doberman Pinscher that was limping and, you know, didn't know why the dog was limping, but she's come in several times with injuries that would be consistent with potentially an abusive boyfriend or husband, and at that time she, you know, was wearing sunglasses and had a black eye. 
The woman never admitted to being abused or to her dog being abused, so the incident was not reported to law enforcement. Aside from these general claims of encountering animal abuse, every participant, excluding Dr. Faulk, had interacted with the criminal justice system, and the researcher chose to focus on those interactions, which will be discussed in the following section.

\section{Interaction with the Criminal Justice System}

The second topic that the interview guide covered was the participants' interactions with the criminal justice system. Much like the first topic, this can be broken down into two recurring themes: (1) involvement with the criminal justice system and (2) perception of the criminal justice system's treatment of animal abuse cases. Their involvement usually consisted of caring for an abused animal and providing their professional opinion as testimony, and the outcomes of these cases all led to disappointment. The following is a discussion of those themes.

\section{Involvement with the Criminal Justice System}

Only one participant claimed to have encountered animal abuse in the preceding 18 months; therefore, all participants were asked to discuss every incident where they were involved with the criminal justice system. Table 7 provides a summary of each participant's experience. Dr. Quinn highlighted a case that occurred sometime during the mid-1990s where a family had been reported for hoarding animals. He worked the case on behalf of the Humane Society and accompanied law enforcement so he could notify them of which animals should be confiscated for the safety of their health. When the case went to trial, he was called to testify. For his testimony, he provided his professional opinion regarding the health and well-being of the offenders' pets. He did not follow up on the case following his testimony making him unsure of what the punishment entailed, but he believes the offenders were given 30 days to clean their home and prove they could provide proper care to their pets before they could have some of 


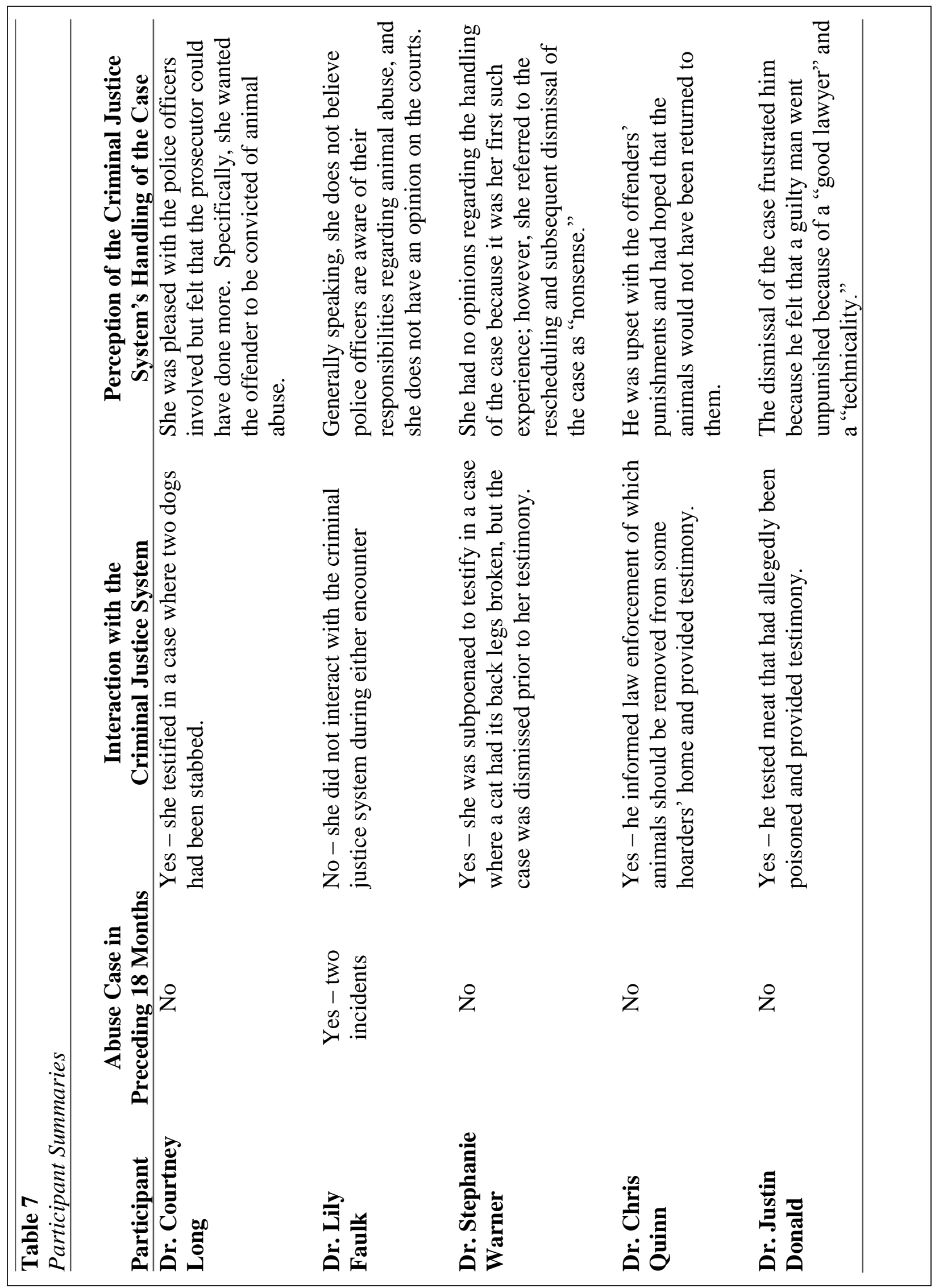

51 
them returned. This was not the resolution he had hoped for:

I remember havin' conversations with the head investigator at the time, that it was bullshit that these people were gonna get their animals back at all. Hoarding's a mental disease. You're not gonna fix that in 30 days.

In fact, none of the participants were happy with the outcome of the trials in which they participated. Dr. Long had cared for two dogs that were stabbed with a machete sometime during 2012 or 2013 . The dogs were presented to her at the animal emergency clinic by local police. She was informed that the two dogs escaped from the backyard because a guest of their owners' cookout had left the gate open. Witnesses stated that the two dogs playfully approached a man walking his dog, and the man promptly pulled out the knife and stabbed the two dogs. Dr. Long cared for the dogs and was subpoenaed to testify. Prior to trial, the defense attorney, who she described as "very strange," summoned her to his office so that he could question her. She claimed that the attorney asked her about dog breeds and explained to her that he believed the breed of the two victims were a very aggressive breed. The attorney was attempting to create a self-defense narrative, but she could not "say that [she] felt that way in any way, shape, or form." According to her, failing to go along with the narrative frustrated the attorney very quickly, so he informed her she could leave. Dr. Long, and the manager of her office who was nearby during the interview, stated that the man was ultimately convicted and sent back to prison but not for animal abuse. The offender was already a felon and, as a condition of his parole, not allowed to be in possession of a knife of that size; therefore, he was convicted of violating his parole and not for animal abuse. The officer manager also claimed that the offender was ordered to pay restitution to the owners of the victims to cover the cost of medical expenses, but he never did.

Dr. Donald also took issue with an attorney during the only case he was involved in throughout the last decade. A man had brought some meat that had allegedly been poisoned into 
Dr. Donald's office. Following a dispute with his neighbor, his dogs became very ill, and he found raw meat that had been thrown into his backyard. Dr. Donald examined the meat which tested positive for antifreeze. At this point, law enforcement was contacted, and the case went to trial. The participant was subpoenaed to testify, and he did so by providing his professional opinion and an explanation for the tainted meat. During the trial, the defendant's attorney asked Dr. Donald to testify. The purpose of this was to show that a proper chain of custody for the allegedly poisoned meat had never been established since it was brought to a veterinarian before it was brought to law enforcement. The failure to establish a chain of custody for a key piece of evidence ultimately led to the defendant not being convicted of animal abuse even though witnesses allegedly saw him throwing the meat into the backyard. As Dr. Donald put it, "[i]t got thrown out of court because of a good attorney."

Dr. Warner was once subpoenaed to testify on behalf of an animal she cared for during the late 1990s; however, the day of trial, the court "pulled some nonsense and rescheduled it" before subsequently dismissing it. The case involved a man that had thrown a cat into the air, and, upon landing, the cat's back legs were broken. She provided care for the cat when it was presented to her, wrote a report describing the injuries to the cat and the care she provided, and submitted the report to the Humane Society. This case is particularly disturbing because of the offense for which the offender ultimately went to prison. Though this case was ultimately dismissed, several years later, the offender and his partner at the time murdered her three children, which earned him a life sentence without the possibility of parole.

\section{Perceptions of the Criminal Justice System's Treatment of Animal Abuse Cases}

Regardless of whether a participant had experience dealing with the criminal justice system, they were asked to discuss how they perceived its treatment of animal abuse cases. 
Virtually everyone has an opinion on the criminal justice system whether they have encountered it or not, and it would be a mistake to constrain this analysis to only the participants that had experience with the system. One can know a great deal about something without having firsthand experience with it. Additionally, participants were asked to describe what they believed an acceptable response to animal abuse consisted of. As will be discussed, the participants did not appear to believe that the criminal justice system had done a satisfactory job, and those opinions were largely influenced by their experiences.

Law Enforcement. Although the participants appeared to be frustrated with the criminal justice system, a few participants did believe that police officers' responses to animal abuse were sufficient in their experiences. Dr. Long believed that,

Most of the police officers are invested and definitely seem to care about the well-being of the animal and the case and things like that. Typically, if they're not that invested, I feel like they don't bring the animal to us, they instead go to Animal Control.

It is important to note that she was referring to the police officers who bring abused animals into either her general practice or the emergency clinic. She believes that there are officers out there who do not care about animal well-being, but she did not specify whether these officers outnumbered the officers that cared. Dr. Donald was not convinced that police officers cared for animals' well-being. He stated,

[Law enforcement's] response to me when they talk about these cases where they have to go out and, you know, actually investigate the abuse, it's a lot like going out to hear the complaints of divorcing couples over children. It's horrible; they really don't want to deal with it.

He then pointed out that he was not sure if that was because police officers genuinely did not care for animal well-being or if it was because they did not want to take animal abuse on as their responsibility since their job was already exhausting. Dr. Faulk questioned whether police understand how they are supposed to handle animal abuse cases or when they are supposed to let 
Animal Control, the Humane Society, or another animal welfare organization handle the case.

Dr. Long did not believe that there was a disconnect between law enforcement and animal welfare agencies but rather between law enforcement and state's attorneys' offices. She felt as if the police were doing everything they could and then presenting the case to the state's attorney only to have them disregard it.

The Courts. While some participants had a positive opinion about law enforcement, none of them felt positively about the court system. Specifically, participants were frustrated with prosecuting attorneys and their inability to or indifference towards pursuing animal abuse cases: very little was said regarding judges. Dr. Long felt as if prosecutors were hesitant to pursue animal abuse cases because it is difficult to secure a conviction, and they want to be certain that they will secure a conviction prior to pursuing a case. Rather than pursuing animal abuse charges, she believes that prosecutors go after crimes they feel are easier to convict on. For instance, the prosecutors in the trial she was a part of convicted the offender on a violation of his parole because doing so is very simple. It bothers her a great deal when animal abusers are convicted of secondary crime they commit during the commission of animal abuse and not the abuse itself. This unwillingness to prosecute affects her daily work to an extent. As previously mentioned, when she hears of potential abuse that she personally has not witnessed, she directs the person to notify the appropriate party rather than get involved, but even then, she is not confident that anything will come of the situation: "I guess you kinda get pessimistic as you go along." It also bothers her that animal abusers usually receive "a slap on the wrist," and she is not alone. Dr. Quinn concurred, saying this of his experience with the criminal justice system, I remember having strong opinions that animal abuse was not getting treated as seriously as it should. At the time, I was $100 \%$, and if it hasn't changed, would still be $100 \%$, that they don't take it seriously enough. 
Dr. Warner believes that the justice system prioritizes animal victims much lower than human victims, which results in animals being "left behind" because prosecutors determine that pursuing animal abuse cases is not worth their time. She believes that,

[T] he courts are full of other things that, I don't wanna say are more important because I think it's terrible, and nobody wants to see an animal suffer, but when it's an animal versus a person, I think the courts tend to lean more towards taking care of issues that involve people directly, and so a lot of animal abuse cases don't get addressed.

She cited Illinois' fiscal crisis as an explanation for why animal abuse cases are designated low priority and thrown to the wayside. Dr. Donald also mentioned Illinois' financial situation as a possible explanation as to why animal abuse is not pursued in the criminal justice system. Additionally, he feels as if judges must "look far and wide" to find legal precedent for punishing animal abusers and that prosecutors must overcome a lack of precedents as well. Dr. Faulk did not have any opinions regarding the court system outside of her belief that the juvenile justice system is too lenient because she did not have any first-hand experience with the courts.

Participants had very little to say about animal protection laws. The only aspect of laws that was discussed was the fact that animals are viewed as property. Dr. Faulk stated that animals maintaining property status "irks" her. Dr. Donald was also upset with animals' property status, exclaiming, "[y]ou can eat the damn thing if you wanted to!” Dr. Quinn was not excited about animals being viewed as property; however, he does not necessarily believe that it is a bad thing. He believes veterinarians benefit hugely by animals' property status because it prevents them from being sued for malpractice. To be sure, he believes that animals should be considered victims of crime when they are abused rather than the owner being considered a victim because their property was damaged. Dr. Long believes the property status of animals has led to a precedent where the court system does not punish abusers; however, she does not believe animals should be considered anything other than property because of the potential for litigation. 
Desired Changes. Though some participants offered more suggestions than others, all but one participant discussed the changes they would like to see the criminal justice system to make when handling animal abuse cases. Dr. Warner stated that it would be nice if animal abusers were punished, and she thinks early intervention is crucial for young animal abusers. If the criminal justice system immediately intervenes when a child abuses an animal, she believes the likelihood that the child commits subsequent interpersonal violence is reduced. To note, she does not believe that intervention would have stopped the man who threw the cat in the air from murdering three children, presumably because he was an adult and already set in his ways. Dr. Long also believes that the criminal justice system should take the early signs of animal abuse more seriously. She also believes that the criminal justice system must prove to society that, if you harm an animal, you will be punished. According to her, many people do not care about the well-being of animals; therefore, they must be made aware that abusing an animal will be accompanied by unpleasant consequences. Ideally, animal abusers would be punished for abusing animals, but, realistically, she understands that to ensure they are punished, sometimes you must accept that animal abusers will be convicted of the secondary crimes they committed while in the commission of animal abuse and not the abuse itself. In a perfect world, animal abusers would receive psychiatric treatment, but she is aware that mental health care is lacking in the United States.

Much like Drs. Warner and Long, Dr. Quinn believes it is crucial for the criminal justice system to intervene early in the lives of animal abusers. As he put it, "[s]tart picking these people up early. Don't wait until they walk into a mall, you know, with a 12-gauge." Animal abusers, he noted, are more likely to bully others, abuse their children, and/or commit some other type of violent crime. He argued that subsequent interpersonal violence could potentially be 
avoided if the criminal justice system would simply take note of and act on the "red flags" that animal abusers are displaying. If Dr. Quinn were to have his way, the criminal justice system would come down much more harshly on animal abusers because abusing animals "should make things very difficult for you for the rest of your life." One suggestion he made was for all forms of animal abuse to be considered a felony, which he believes would serve as a deterrent for some. Another suggestion was similar to a punishment often given sex offenders in that he would like for animal abusers to be required to notify any potential employer that he or she was convicted of animal abuse. He believed, again, this could serve as a deterrent for some and would make employers aware of what that person was capable of. While Dr. Quinn was a proponent for more severe punishments, he does not want to see the criminal justice system "ruin" peoples' lives. If a young child abuses an animal, he believes that child is "broken" and that the criminal justice system should try to figure out what led to that.

He questioned,

What if this kid's gettin' the shit kicked out of him by his dad every day in his house? Somewhere there's a problem that needs to be solved.

If an adult abuses an animal, he thinks it is important for that person's children and partner to be interviewed to see if they are also being abused. Although Dr. Quinn had several suggestions for the criminal justice system, he wondered if he was being unrealistic by expecting these changes. He said with a sense of defeat in his voice,

I know it's probably a dream to think that the justice system would be able to take that burden on, but I just think we're missing a big window of opportunity to find people who are potentially violent and dangerous to society and their red flag was that they were horrible to animals.

The feeling that his line of thinking was naïve resulted from two issues: 1) he believes that there are problems more important than animal abuse that the criminal justice system must solve; and, 
2) the parties that are responsible for dealing with animal abuse do not want to deal with it. Specifically, he does not believe that most veterinarians would choose to handle animal abuse because, as previously mentioned, they are emotionally battered during their day job and want to avoid it. The last thing he wants to see when he goes home at night is animal abuse.

Dr. Donald would like to see changes to our legal definitions of animal abuse, the certainty of punishment for animal abusers, and the standards of care permitted. For this veterinarian, the ambiguity found in animal protection laws is problematic because veterinarians are often left wondering if what they are witnessing is abuse. If the laws were more specific, veterinarians might be better equipped to combat animal abuse. He would also like for animal protection laws to guarantee punishment for animal abusers. The punishments do not necessarily have to be severe, but they must be certain. One penalty he would like to see is for animal abusers to be prevented from owning pet for a certain amount of time. It is frustrating to him that a person like Michael Vick can own another animal after what he did. Finally, Dr. Donald would like to see some sort of minimum standards of care for owning a pet not only signed into law but ingrained into our society. His frustration was obvious when he rhetorically questioned, "What are the requirements...for a dog owner? What are they held to? Nothing!" It is his hope that universally accepted standards of care would result in less pet neglect. 


\section{CHAPTER V}

\section{DISCUSSION}

The purpose of this study was to explore veterinarians' perceptions of the treatment of animal abuse cases in the criminal justice system. Additionally, the researcher sought to learn of what veterinarians believed an appropriate response to animal abuse cases in the criminal justice system would consist of. The data were collected through the use of semi-structured qualitative interviews conducted with veterinarians employed in McLean County, Illinois. Only one prior study that examined veterinarians and the criminal justice system was known to the researcher; therefore, semi-structured were the most appropriate method of data collection as there was a dearth of literature to guide the researcher. Interviews gathered demographical data as well as information on veterinarians' familiarity with animal abuse and experience with the criminal justice system. This final chapter will discuss the study's findings, limitations, and implications.

\section{Discussion}

The first part of the interviews can be broken down into two recurring themes: familiarity with animal abuse and the handling of animal abuse. Understanding how familiar veterinarians are with animal abuse is important because a person's knowledge of a topic almost certainly influences their opinions regarding that topic. For instance, if a participant was completely oblivious to the issue of animal abuse, their perceptions of the criminal justice system's response to it might be completely misguided.

The interviews revealed that all participants had far more experience handling instances of animal neglect than physical abuse. They often differentiated between the two, hinting at 
physical abuse being the more heinous form of animal abuse, but they maintained that both were an issue. The FBI (2016) began tracking animal cruelty as its own statistic at the beginning of 2016, so there are no official national statistical patterns that would display which form of abuse was the most common. Currently, Pet-Abuse.com's (2016) Cruelty Database is the most comprehensive dataset of animal abuse, and, although there are numerous methodological flaws with their data collection procedures, their findings do indicate that neglect is the most common form of animal abuse, contributing to nearly one-third (32.4\%) of all abuse known to them. The participants' estimates were much higher than one-third, but it is entirely plausible that agencies such as the Humane Society or the Society for the Prevention of Cruelty to Animals encounter the majority of physical abuse while veterinarians encounter most cases of neglect. Hopefully the FBI's data will shed light on whether this is the case.

Regardless of whether neglect or physical abuse is more common, it appears, at least in the experiences of these five participants, veterinarians rarely encounter animal abuse. The abuse that they do encounter is usually through the work they do at emergency clinics or animal shelters and rescue agencies. One participant claimed to have never encountered it in private practice, while highest estimate of encountering animal abuse in private practice was still less than $5 \%$ of all animals seen. A few of the participants suggested that veterinarians are insulated from animal abuse because many who abuse animals do not bring their pet to the veterinarian or would not admit to the abuse.

The second recurring theme from the first part of the interview was how veterinarians handled animal abuse when they encountered it. Understanding how veterinarians handled animal abuse was important because it gave the researcher some insight into how likely the participants were to report abuse to the criminal justice system. Generally, the participants did 
not report animal abuse at all unless they were certain that what they were witnessing constituted abuse. This was the result of ambiguous definitions of animal abuse and the belief that the criminal justice system would fail to act on the abuse. Pet-abuse.com's (2016) Cruelty Database indicates that veterinarians only reported $0.008 \%$ of the abuse cases where a reporting party was known. Typically, when the participants did witness animal abuse, they documented all relevant information, and, if the abuse they witnessed was neglect, they would attempt to educate the pet owner on the standards of sufficient care. These findings are in line with the findings of Donley et al.’s (1999) survey of veterinarians.

Participants of this study were unlikely to report animal abuse to law enforcement likely because of the belief that, as Dr. Long put it, "nothing will happen about it." Donley et al. (1999) found that just over three-fourths $(77.3 \%)$ of their participants would be more willing to file a report of animal abuse if they had confidence in the investigating agency. The results from that survey also found that $73.6 \%$ of participants would be more willing to make a report if they were confident that it would remain confidential, and $38.2 \%$ indicated that they feared potential repercussions (e.g. legal liability for slander, violations of confidentiality, risk to staff from abusive clients) that could accompany filing a report that did not remain confidential (Donley et al, 1999). Two participants from this study discussed the potential for legal liability; therefore, it is entirely plausible that such a fear prevented them from filing a report. They all preferred to bring instances of animal abuse, suspected or actual, to the attention of animal welfare agencies, such as the Humane Society or Animal Control. It is possible that veterinarians trust and feel more comfortable with animal welfare agencies rather than they do with law enforcement agencies. 
The unwillingness to report or inability to detect animal abuse could potentially stem from the lack of training veterinarians receive regarding animal abuse. None of the participants received official training throughout veterinary school or their time spent working in private practice. One veterinarian did admit to receiving training but stated that the training was voluntary. It is important to note that all but one participant attended the same veterinary education program, so it is possible that other veterinary schools educate on how to detect and handle animal abuse. The participant who completed veterinary school most recently did state that animal was passively discussed several times throughout her veterinary education, which could indicate that veterinary schools are beginning to add animal abuse to their curriculum. Donley et al. (1999) found that training, or the lack thereof, was an issue as well. One-third $(34.5 \%)$ of participants felt they required additional training in detecting abuse, and the clear majority $(84.5 \%)$ believed that training in detecting animal abuse should be a component of veterinary medicine education (Donley et al., 1999). Training may assist veterinarians overcoming the ambiguous language that is frequently found in animal protection laws, which was cited as an issue by participants of the current study. Three-fourths (76.4\%) of Donley et al's (1999) participants were unsure of when to differentiate between poor care and neglect, and $70 \%$ reported that they would be more likely to report neglect if there were published criteria available to them. The participants in this study also cited the lack of universally accepted criteria for determining what was neglect as an issue.

Participants were asked to discuss all incidents of animal abuse they had encountered during the 18 months preceding their interview, but only one participant was able to identify a specific incident of animal abuse within that parameter. As a result, the researcher asked the participants to identify any instances of animal abuse they could recall, which garnered a 
response from the other four participants, all of which had encountered the criminal justice system. This finding made it apparent that, even though veterinarians rarely encounter animal abuse, they are involved with the criminal justice system far less frequently. The only veterinarian that identified incidents of abuse in the year and a half prior to her interview was not involved with the criminal justice system in the capacity of a veterinarian throughout her entire 13-year career.

The second part of the interviews resulted in two recurring themes as well: involvement with the criminal justice system and perception of the criminal justice system's treatment of animal abuse cases. As noted above, four participants have been involved with the criminal justice system, and they were asked to discuss their experiences. Typically, their involvement consisted of caring for an injured animal, writing a report that explained the injuries of and care provided to the animal, and offering their professional opinion as testimony. Interestingly, of those four, only one went to trial over a case of neglect even though neglect was the form of animal abuse most frequently encountered. The other three participants were involved in trials centered on physical abuse. Furthermore, of all the cases that did go to trial, only one participant brought the case to the police while the other three had the case brought to them. This lends support to the idea that veterinarians are insulated from animal abuse as a few of the participants had suggested.

Following the discussion of their involvement with the criminal justice system, all participants were asked to describe how they perceived the criminal justice system's treatment of animal abuse cases. The four participants that had experience with the justice system could speak firsthand, but the participant that lacked this experience was asked to speak of her perceptions of the criminal justice system's response in general. The researcher would have 
been remiss if this part of the analysis had been constrained to the veterinarians with firsthand experience. Law enforcement was the only facet of the criminal justice system that the participants had anything positive to say about. One veterinarian believed that, generally, police officers genuinely care about the well-being of animals, but they are unable to do much because the court system is unwilling to help. Another veterinarian stated that the impression he has received from police is that they are annoyed when required to handle animal abuse cases, and a third veterinarian questioned whether police are aware of their duties regarding abused animals. There was a consensus when asked about the court system, however. All participants felt that the courts, prosecutors in particular, could be doing much more to combat animal abuse. Participants believed that prosecutors were unwilling to accept animal abuse cases because it was difficult to secure a conviction, which led to a precedent of not pursuing such cases. There was very little said about judges, but the perception was that, since prosecutors would not prosecute animal abuse, judges' hands were tied, thus absolving them.

At the conclusion of each interview, participants were asked to explain any changes they would like to see the criminal justice system make to be more efficient in combatting animal abuse. Generally speaking, they all possessed the desire to see the criminal justice system take animal abuse cases more seriously. Another suggestion that was resonated by a few participants was that the justice system should intervene as early as possible with animal abusers to decrease the likelihood that they commit subsequent interpersonal violence. Some of the veterinarians interviewed would also like to see more severe punishments because they believe it would result in a deterrent effect. To be sure, they believe it was in the justice system's best interest to understand why a person abuses animals and attempt to correct those issues and not just be punitive. There were various other suggestions made by these five participants, but what is 
important to take away is that they are unhappy with the current application of justice, and they would like to see it applied differently.

\section{Limitations}

As with any study, this study had limitations that should be noted, namely the study's sample size. The researcher had hoped for a larger number of participants. The county that served as the research site is home to only 39 veterinarians employed by 17 veterinary clinics, but only five veterinarians agreed to participate. However, the in-depth nature of each interview enabled the researcher to obtain valuable information and provided insight into the perceptions of veterinarians. Another limitation of this study is that it only showcases the experiences of veterinarians within McLean County. Other vets may have different perceptions and experiences. In addition, there was a lack of racial heterogeneity. Individuals of different racial and ethnic backgrounds could have brought a different perspective to the results of this research. Another limitation resulting from participant demographics was related to their experience as veterinarians. The participant with the least amount of experience still had a considerable amount with ten years on the job. It is possible that younger veterinarians' experiences with and perceptions of the criminal justice system differ from those of older veterinarians. Additionally, veterinarians who completed veterinary school recently may have received training in detecting or handling animal abuse, whereas the participants in this study did not. Official training would almost certainly affect a veterinarian's experiences with animal abuse.

Respondent bias is also a potential limitation that could have affected the study's results. It is possible that there are characteristics possessed by these five participants that led them to participate in the study that would result in experiences different from the other 34 veterinarians 
in the county. It is plausible that these veterinarians chose to participate because they had a poor experience with the criminal justice system and wanted to express their frustrations.

While the study's sample size does hinder the study's implications, the findings can serve as a foundation for future research on the subject, which is significant given the dearth of relevant studies. The researcher intends to construct a survey based on the results of this study, which will be distributed to an array of veterinarians. Doing so will allow the research to expand upon the current findings further reducing the wide gap in the literature.

\section{Recommendations and Conclusion}

Veterinarians have been virtually absent from the study of animal abuse in social science research. Much of such research has historically focused on the consequences for humans, with little to no regard for how animals are treated or how veterinarians, a population uniquely positioned within society to champion for animals, perceive the treatment of animal abuse cases in the criminal justice system. The findings indicate that veterinarians are not pleased with the current treatment of animal abuse cases in the criminal justice system. To better address the problem of animal abuse, social scientists and the criminal justice system could work with veterinarians. Law enforcement agencies, prosecutors, judges, and veterinarians could form a partnership, whether it be an advisory board, committee, or simply a forum for discussion, with the goal of creating a more effective of combatting animal abuse. Such a partnership would allow all parties to communicate with one another and make suggestions, express frustrations, and forge an alliance. The results of this study indicate that veterinarians may not feel comfortable with or see the purpose in reporting animal abuse to the criminal justice system. If veterinarians could interact with the justice system outside of making a report, it is possible they would become more comfortable with law enforcement and/or the court system and be more 
willing to file a report. If such a partnership is not a possibility, it may be beneficial to give animal welfare investigators (e.g. Humane Society, Society for the Prevention of Cruelty to Animals) policing powers. The participants in the current study appeared to be more comfortable approaching such agencies, which could result in an increase in reporting. Required training for law enforcement agencies would also be beneficial. The Illinois Department of Agriculture's Bureau of Animal Health and Welfare (n.d.) has created a PowerPoint document that outlines the state's animal protection laws and law enforcement's responsibility in addition to providing examples of various types of abuse. Requiring law enforcement to review this document would be an excellent starting point. Ideally, law enforcement agencies would dedicate resources toward creating an animal abuse investigator position[s] that would enable an officer[s] to focus solely on animal abuse.

It is the researcher's hope that these findings will lead to an increased interest in the study of animal abuse as well as provide the necessary framework for likeminded researchers. Based on the findings from this study, future scholars could choose to investigate several topics. First, it would be greatly beneficial to discover which forms of animal abuse are truly the most common. Ideally, the FBI's collection of animal abuse data will help identify which forms of abuse occur with the greatest frequency. Second, researchers may want to look further into whether veterinarians in private practice are insulated from animal abuse. The results of this study would suggest that they are. If one were to investigate this, it would be wise to survey veterinarians as well as law enforcement and animal welfare agencies in a specific area and compare the reported rates of animal abuse. Third, it would be interesting in addition to being beneficial to better understand why some veterinarians decide against reporting animal abuse. Understanding their justifications could potentially lead to a method for increasing the reporting 
of animal abuse. Fourth, researchers should consider which type of animal abuse, physical abuse or neglect, is more likely to result in criminal charges and conviction. The results of this study indicate that physical abuse is more likely to end up in court even though neglect appears to occur with greater frequency. Additionally, it would be beneficial to learn of who, veterinarians or law enforcement, are more likely to initiate the investigations of animal abuse that ultimately go to trial. Perhaps one population has greater success combatting animal abuse. Finally, and perhaps most importantly, social scientists should research law enforcement and determine whether they understand how to handle instances of animal abuse. As one participant had suggested, police officers may not know what their responsibility is when animal abuse is encounter. Should animal abuse agencies receive greater jurisdiction, or should law enforcement agencies deal with the issue exclusively?

The current study adds to the literature and can provide a starting point for future research. The researcher hopes that the findings lead other scholars to expand upon this study and contribute further to the literature. It is a mistake to ignore veterinarians' opinions on the treatment of animals, an understudied population in the social sciences. The data indicate that the criminal justice system can do better, and social scientists are in a position to discover how that can happen. 


\section{REFERENCES}

Adams, C. J., \& Donovan, J. (1995). Introduction. In Carol J. Adams and Josephine Donovan (eds.), Animals and women: Feminist theoretical explorations. Durham, N.C.: Duke University Press.

Agnew, R. (1998). The causes of animal abuse: A social-psychological analysis. Theoretical Criminology, 2(2), 177 - 209.

Akpan, K. (2014). The National Sheriff's Association has launched the National Law Enforcement Center on Animal Abuse (NLECAA). Sheriff, 66(6), 32 - 33.

Allen, M. D. (2005). Laying down the law? Interest group influence on state adoption of animal cruelty felony laws. Policy Studies Journal, 33(3), 443-457.

Alleyne, E., Tilston, L., Parfitt, C., \& Butcher, R. (2015). Adult-perpetrated animal abuse: Development of a proclivity scale. Psychology, Crime, \& Law, 21(6), 570-588.

American Pet Products Association (APPA). (n.d.). Pet Industry Market Size \& Ownership Statistics. Retrieved from http://www.americanpetproducts.org/press_industrytrends.asp.

American Veterinary Medicine Association. (n.d.). Market Research Statistics: U.S. Veterinarians 2016. Retrieved from https://www.avma.org/KB/Resources/Statistics/Pages/Market-research-statistics-USveterinarians.aspx.

Animal Legal Defense Fund. (2015, December 2016). 2015 U.S. animal protection laws rankings: Comparing overall strength \& comprehensiveness. Retrieved from http://aldf.org/wp-content/uploads/2015/12/Rankings-Report-2015.pdf.

Arkow, P. (2003). Breaking the cycles of violence: A guide to multi-disciplinary interventions. A handbook for child protection, domestic violence and animal protection agencies. Alameda, CA: Latham Foundation.

Arkow, P. (2014). Form of emotional blackmail: Animal abuse as a risk factor for domestic violence. Family \& Intimate Partner Violence Quarterly, 7(1), 7-13.

Arkow, P., \& Lockwood, R. (2013). Definitions of animal cruelty, abuse, and neglect. In Brewster, M. P. \& Reyes, C. L. (Eds.), Animal cruelty: A multidisciplinary approach to understanding (pp. 3-24). Durham, NC: Carolina Academic Press.

Arluke, A. (2012). Interpersonal barriers to stopping animal abuse: Exploring the role of adolescent friendship norms and breeches. Journal of Interpersonal Violence, 27(15), 2939-2958. 
Arluke, A., Levin, J., Luke, C., \& Ascione, F. R. (1999). The relationship of animal abuse to violence and other forms of antisocial behavior. Journal of Interpersonal Violence, 14(9), 963-975.

Arluke, A., \& Madfis, E. (2014). Animal abuse as a warning sign of school massacres: A critique and refinement. Homicide Studies, 18(1), 7-22.

Ascione, F. R. (1993). Children who are cruel to animals: A review of research and implications for developmental psychopathology. Anthrozoös, 6(4), 226-247.

Ascione, F. R., \& Shapiro, K. (2009). People and animals, kindness and cruelty: Research directions and policy implications. Journal of Social Issues, 65(3), 569-587.

Bandura, A. (1990). Selective activation and disengagement of moral control. Journal of Social Issues, 46, 27-46.

Beirne, P. (1999). For a nonspeciesist criminology: Animal abuse as an object of study. Criminology, 37(1), 117-147.

Bentham, J. (1789). Introduction to the principles of morals and legislation. In Burns, J. H., \& Hart, H. L. A. (Ed.), An introduction to the principles of morals and legislation. London; New York : Methuen, [1982] c1970.

Berry, C. (2014, March 14). All 50 states now have felony animal cruelty provisions! Retrieved from http://aldf.org/blog/50-states-now-have-felony-animal-cruelty-provisions/

Brewster, M. P. \& Grugan, S. (2013). Emerging issues and future directions in animal cruelty. In Brewster, M. P. \& Reyes, C. L. (Eds.), Animal cruelty: A multidisciplinary approach to understanding (pp. 347-371). Durham, NC: Carolina Academic Press.

Burchfield, K. B. (2016). The sociology of animal crime: An examination of incidents and arrests in Chicago. Deviant Behavior, 37(4), 368 - 384.

Cazaux, G. (1999). Beauty and the beast: Animal abuse from a non-speciesist criminological perspective. Crime, Law \& Social Change, 31, 105-126.

Dadds, M. R., Whiting, C., \& Hawes, D. J. (2006). Associations among cruelty to animals, family conflict, and psychopathic traits in childhood. Journal of Interpersonal Violence, 21(3), 411-429.

Darst, A. (Winter 2011). The difficult response. Kentucky Law Enforcement Magazine, 10(4), 20-27.

Donley, L., Patronek, G. J., \& Luke, C. (1999). Animal abuse in Massachusetts: A summary of case reports at the MSPCA and attitudes of Massachusetts veterinarians. Journal of Applied Animal Welfare Science, 2(1), 59-73. 
Eisenstein, Y. (2013). Animal cruelty and the law: Prohibited conduct. In Brewster, M. P. \& Reyes, C. L. (Eds.), Animal cruelty: A multidisciplinary approach to understanding (pp. 45-61). Durham, NC: Carolina Academic Press.

Farve, D. (2013). The history of anti-cruelty laws: Concepts of animal welfare and animal rights. In Brewster, M. P. \& Reyes, C. L. (Eds.), Animal cruelty: A multidisciplinary approach to understanding (pp. 109-123). Durham, NC: Carolina Academic Press.

FBI. (2016, February 1). Tracking animal cruelty. Retrieved from https://www.fbi.gov/news/stories/2016/february/tracking-animal-cruelty/tracking-animalcruelty.

Felthous, A. R., \& Kellert, S. R. (1986). Violence against animals and people: Is aggression against living creatures generalized? Bulletin of the American Academy of Psychiatry \& Law, 14, 1, 55-59.

Felthous, A. R., \& Kellert, S. R. (1987a). Childhood cruelty to animals and later aggression against people: A review. American Journal of Psychiatry, 144, 710-717.

Felthous, A. R., \& Kellert, S. R. (1987b). Psychosocial aspects of selecting animal species for physical abuse. Journal of Forensic Science, 32, 1713-1723.

Fitzgerald, A. J., Stevenson, R., \& Verbora, A. R. (2013). Sociological theories of animal abuse. In Brewster, M. P. \& Reyes, C. L. (Eds.), Animal cruelty: A multidisciplinary approach to understanding (pp. 285-306). Durham, NC: Carolina Academic Press.

Flynn, C. P. (1999). Animal abuse in childhood and later support for interpersonal violence in families. Society and Animals, 7(2), 161-172.

Flynn, C. P. (2012). Understanding animal abuse: A sociological analysis. Brooklyn, NY: Lantern Books.

Grant, H., Lavery, C., \& Spanjol, K. (2015). Critical understandings about animal cruelty for law enforcement practitioners. Journal of Law Enforcement, 4(5), 1-12.

Haden, S. C., \& Scarpa, A. (2005). Childhood animal cruelty: A review of research, assessment, and therapeutic issues. Forensic Examiner, 14(2), 23-32.

Henry, B. C. (2004). The relationships between animal cruelty, delinquency, and attitudes toward the treatment of animals. Society \& Animals, 12(3), 185-207.

Hensley, C., \& Tallichet, S. E. (2005a). Animal cruelty motivations: Assessing demographic and situational influences. Journal of Interpersonal Violence, 20(11), 1429-1443. 
Hensley, C., \& Tallichet, S. E. (2005b). Learning to be cruel?: Exploring the onset and frequency of animal cruelty. International Journal of Offender Therapy and Comparative Criminology, 49(1), 37-47.

Humane Society of the United States. (2002). First strike: The connection between animal cruelty and human violence. Retrieved from http://www.hsus.org/ace/15828.

Humane Society of the United States. (2004). Animal cruelty laws: Where does your state stand? Retrieved from http://www.hsus.org/ace/19839.

Illinois Department of Agriculture's Bureau of Animal Health and Welfare. (n.d.). Animal law awareness for law enforcement and other governmental agencies. Retrieved from https://agr.state.il.us/AnimalHW/LawEnforcementTraining.pdf.

Kavanagh, P. S., Signal, T. D., \& Taylor, N. (2013). The Dark Triad and animal cruelty: Dark personalities, dark attitudes and dark behaviors. Personality and Individual Differences, $55,666-670$.

Livingston, M. (2001). Desecrating the ark: Animal abuse and the law's role in prevention. Iowa Law Review, 87(1), 1-74.

McDonald, S. (2011). Childhood Animal Abuse and Violent Criminal Behavior: A Brief Review of the Literature. Retrieved from http://www.mass.gov/eopss/docs/doc/researchreports/briefsstatsbulletins/summaryofanim alabuseliteraturefinal.pdf.

Navarro, J., \& Schneider, J. L. (2013). Animal cruelty for profit. In Brewster, M. P. \& Reyes, C. L. (Eds.), Animal cruelty: A multidisciplinary approach to understanding (pp. 127-155). Durham, NC: Carolina Academic Press.

Padgett, D. K. (1998). Qualitative methods in social work research: Challenges and rewards. Thousand Oaks, CA, US: Sage Publications, Inc.

Pet-Abuse.com. (2016). Cruelty Database. Retrieved from http://www.petabuse.com/pages/cruelty_database/statistics.php.

Pinel, P. (1962). Treatise on insanity. New York: Hafner. (Original work published 1806)

Sherry, C. J. (1994). Animal rights: A reference handbook. Santa Barbara, CA: ABC-CLIO, Inc.

Sykes, G. M., \& Matza, D. (1957). Techniques of neutralization: A theory of delinquency. American Sociological Review, 22, 664-670.

Peter Singer, Dierenbevrijding, (Breda: Uitgeverij De Geus, 1994), (original: Animal Liberation, 1990, revised ed. of 1975). 
Tallichet, S. E., Hensley, C., \& Singer, S. D. (2006). Unraveling the methods of childhood and adolescent cruelty to nonhuman animals. Society \& Animals, 13(2), 91-107.

Taylor, N. (2011). Criminology and human-animal violence research: The contribution and the challenge. Critical Criminology, 19(3), 251-263.

Thompson, K. L. \& Gullone, E. (2006). An investigation into the association between the witnessing of animal abuse and adolescents' behavior toward animals. Society \& Animals, 14(3), 221-243.

Vaughn, M. G., Fu, Q., DeLisi, M., Beaver, K. M., Perron, B. E., Terrell, K., \& Howard, M. O. (2009). Correlates of cruelty to animals in the united states: Results from the national epidemiologic survey on alcohol and related conditions. Journal of Psychiatric Research, $43,1213-1218$.

Volant, A. M., Johnson, J. A., Gullone, E., \& Coleman, G. J. (2008). The relationship between domestic violence and animal abuse: An Australian study. Journal of Interpersonal Violence, 23(9), 1277-1295.

Walters, G. D. (2013). Testing the specificity postulate of the violence graduation hypothesis: Meta-analyses of the animal cruelty-offending relationship. Aggression and Violent Behavior, 18, 797-802.

Wright, P. (2012, August 31). Ore. court rules animals aren't just property. Retrieved from http://www.petnews.com.au/Newsletter-31st-August2012/Ore.\%20court\%20rules\%20animals\%20aren't\%20just\%20property.pdf

Wright, P. (2015, March 23). Oregon Supreme Court nixes rulings that animals can be victims. Retrieved from http://www.eastoregonian.com/eo/local-news/20150323/oregon-supremecourt-nixes-rulings-that-animals-can-be-victims. 


\section{APPENDIX A: INTERVIEW GUIDE}

\section{Demographics}

1. Gender

2. Race

3. Job title

a. How many years have you worked in that position?

b. How many years have you worked with animals?

\section{Experiences with Animal Abuse}

1. Please describe your professional experience working with animals.

2. Please describe your familiarity with animal abuse in your current position.

3. Please explain what type of training you received in detecting animal abuse.

4. Please describe the procedures you follow in handling/reporting animal abuse in your current position.

5. Please describe any incidents of animal abuse you encountered in your current position in the last 18 months.

a. How did you handle those incidents?

\section{Interaction with the Criminal Justice System}

(For those that reported abuse to the criminal justice system in the last 18 months)

1. What was your experience like in interacting with the criminal justice system?

2. Please explain your involvement in the case.

3. Please describe the outcome of the case.

4. What is your perception of the treatment of animal abuse cases in the criminal justice system? (This question will be asked to all participants whether they have reported abuse or not.)

Definition: Animal abuse is any illegal act that contributes to the pain or death of an animal or that otherwise threatens the welfare of an animal. 
Hello,

My name is Dustin Richardson, and I am a graduate student from the Criminal Justice Sciences department at Illinois State University working under the supervision of Dr. Shelly Clevenger.

I am contacting you because I am conducting interviews with veterinarians regarding their professional experiences with animal abuse and the criminal justice system. I hope to learn whether you believe law enforcement and the court system effectively address the issue of animal abuse. Information gathered from your participation will help me determine and design programming needed to help punish and deter animal abuse, as well as provide guidance for future researchers and professors who teach the subject.

Participation in this study is completely voluntary, and any information provided by participants will be kept confidential. Interviews can be conducted in person, at your convenience, or over the phone. They are expected to take about an hour of your time. However, this is only an estimate, and interviews could be shorter or longer.

Please let me know if you would be interested in participating. If you have any questions, please do not hesitate to ask. Thank you for your time and consideration.

\section{Dustin Richardson}

\author{
Illinois State University
}

Department of Criminal Justice Sciences

Campus Box 5250

Normal, IL 61790

217-299-8257

darich1@ilstu.edu
Dr. Shelly L. Clevenger

Illinois State University

422 Schroeder Hall

Normal, IL 61761

724-840-7485

309-428-1068

slcleve@ilstu.edu 


\section{APPENDIX C: VOLUNTARY INFORMED CONSENT FORM FOR INTERVIEW}

\section{Introduction}

Dr. Shelly Clevenger, Illinois State University, and I would like to invite you to participant in a research study. I ask that you please review the following information so that you can make an informed decision in regard to your participation in this project. If you choose to participate, please keep in mind that I would like for you to ask any questions, at any time, about this study, my intentions, and your role as a participant in this study.

\section{Purpose of Study}

The purpose of this study is to learn about and understand the perceptions of and experiences with the criminal justice system's response to animal abuse held by veterinarians. Specifically, I am interested in whether you believe the criminal justice system appropriately reacts to cases of animal abuse and/or what you think the system can do differently to respond more effectively. The data will be used for publications in criminological journals, conference presentations, and to complete a thesis.

\section{Procedures}

I will be asking questions about your professional experiences with animal abuse and the criminal justice system. Interviews are expected to take about an hour of participants' time. However, this is only an estimate, and interviews could be shorter or last longer. With your permission, interviews will be recorded. As soon as interviews are transcribed the recordings will be deleted. I will use quotes in my write up of my research, but no identifying information will be used in future publications. To protect the participants, de-identified data will be stored under lock and key for a period of three years. Identified data is destroyed once transcription occurs.

\section{Risks/Discomforts}

The primary risk of this study is the potential loss of confidentiality; however, the researchers will do everything within their power to ensure this does not happen. During the interviewing process, you will be asked questions pertaining to your professional experiences with animal abuse. There is a possibility that the interview can cause emotional distress as you will be discussing sensitive and potentially painful memories. Some questions may require you to recall graphic images of abused animals. If at any time you feel you cannot continue with the interview or wish to not answer certain questions, your requests will be granted by the interviewer. If you wish to withdraw, all information will be destroyed, if you so wish. You will not experience any negative effects for doing so. Interview sessions will consider the comfort level of the participants and respect each participant's wishes. Interviews will be coded with identification numbers, so that your actual name will not be used. This will help to maintain confidentiality. Information given to me will be stored securely and used for research purposes in academia and to assist the criminal justice system in helping abused animals. Your name will not be disclosed in association with your information given during the interview. However, I will be required to report any information such as: intent to harm oneself or another person, intent to engage in future criminality. 


\section{Benefits}

Some participants may find it cathartic to be given a platform discuss these experiences and voice their opinions about the matter. Additionally, your participation will provide the researchers with information that could potentially better the lives of animals.

\section{Participation}

Participation in this study is completely voluntary. Your decision not to participate will have no negative consequences. If you are willing to participate please sign and date the attached form. A copy of this form will be kept on file in Dr. Clevenger's office on Illinois State's campus. I will provide you with a copy of this form to keep. If you do not wish to proceed with participation in this study, I would like to thank you for your time and consideration of this matter.

Name (Please Print)

Signature

Date 


\section{APPENDIX D: VOLUNTARY CONSENT FORM FOR INTERVIEW}

After reviewing the following information provided by the researcher, I volunteer to participate in this research study and have my interview audio recorded. I understand that information I provide will be kept confidential and no identifying information will be used. I understand that my participation is completely voluntary and that I may withdraw from participation in this study at any time, without any negative repercussions.

Name (Please Print)

Signature

Date

After reviewing the following information provided by the researcher, I volunteer to participate in this research study without having the interview audio recorded. I understand that information I provide will be kept confidential and no identifying information will be used. I understand that my participation is completely voluntary and that I may withdraw from participation in this study at any time, without any negative repercussions.

Name (Please Print)

Signature

Date

I hereby certify that I have explained to the participant the nature of this study, potential benefits, and possible risks associated with participation, and have given the opportunity for questions to be asked and answered in regard to this study.

Signed: Date:

Contact information:

Dustin Richardson

Illinois State University

Department of Criminal Justice Sciences

Campus Box 5250

Normal, IL 61790

217-299-8257

darich1@ilstu.edu
Dr. Shelly L. Clevenger

Illinois State University

422 Schroeder Hall

Normal, IL 61761

724-840-7485

309-428-1068

slcleve@ilstu.edu

Please direct questions about research participants' rights and/or a research related injury or adverse effects to:

The Research Ethics \& Compliance Office

(309) 438-2529

rec@ilstu.edu 


\section{APPENDIX E: WITHDRAWAL STATEMENT}

\section{Please place an $X$ on the line next to which statement reflects your wishes and fill out the corresponding information.}

\section{Withdrawal Statement to allow use of data}

I have chosen to withdraw from this study, but give my permission to the researcher, Dustin Richardson, to use any data collected prior to my decision to withdraw from this study.

Name (Please Print)

Signature

Date

I hereby certify that I have explained to the participant that this information will be used for research purposes and to assist law enforcement in helping abused animals and any file linking names to data will be destroyed, but data will be maintained with no identifiers (way to link names to information).

Signed: Date:

\section{Withdrawal Statement to disallow use of data}

I have chosen to withdraw from this study and for the researcher, Dustin Richardson, to not use any data collected prior to my decision to withdraw from this study. The data will be destroyed immediately following this interview.

Name (Please Print)

Signature

Date

I hereby certify that I have explained to the participant that this information will not be used and any file linking names to data will be destroyed.

Signed:

Date:

\section{Dustin Richardson}

Illinois State University

Department of Criminal Justice Sciences

Campus Box 5250

Normal, IL 61790

217-299-8257

darich1@ilstu.edu
Dr. Shelly L. Clevenger

Illinois State University

422 Schroeder Hall

Normal, IL 61761

724-840-7485

309-428-1068

slcleve@ilstu.edu 